\title{
Population genetic screening programmes: principles, techniques, practices, and policies
}

\author{
Béatrice Godard ${ }^{1,4}$, Leo ten Kate ${ }^{2}$, Gerry Evers-Kiebooms ${ }^{3}$ and Ségolène Aymé*,1 \\ ${ }^{1}$ INSERM SC11, Paris, France; ${ }^{2}$ Department of Clinical Genetics and Human Genetics, Amsterdam, The Netherlands; \\ ${ }^{3}$ Psychosocial Genetics Unit, Department of Human Genetics, University of Leuven, Leuven, Belgium
}

This paper examines the professional and scientific views on the principles, techniques, practices, and policies that impact on the population genetic screening programmes in Europe. This paper focuses on the issues surrounding potential screening programmes, which require further discussion before their introduction. It aims to increase, among the health-care professions and health policy-makers, awareness of the potential screening programmes as an issue of increasing concern to public health.

The methods comprised primarily the review of the existing professional guidelines, regulatory frameworks and other documents related to population genetic screening programmes in Europe. Then, the questions that need debate, in regard to different types of genetic screening before and after birth, were examined. Screening for conditions such as cystic fibrosis, Duchenne muscular dystrophy, familial hypercholesterolemia, fragile X syndrome, hemochromatosis, and cancer susceptibility was discussed. Special issues related to genetic screening were also examined, such as informed consent, family aspects, commercialization, the players on the scene and monitoring genetic screening programmes. Afterwards, these questions were debated by 51 experts from 15 European countries during an international workshop organized by the European Society of Human Genetics Public and Professional Policy Committee in Amsterdam, The Netherlands, 19-20, November, 1999. Arguments for and against starting screening programmes have been put forward. It has been questioned whether genetic screening differs from other types of screening and testing in terms of ethical issues. The general impression on the future of genetic screening is that one wants to 'proceed with caution', with more active impetus from the side of patients' organizations and more reluctance from the policy-makers. The latter try to obviate the potential problems about the abortion and eugenics issues that might be perceived as a greater problem than it is in reality. However, it seems important to maintain a balance between a 'professional duty of care' and 'personal autonomy'.

European Journal of Human Genetics (2003) 11, Suppl 2, S49-S87. doi:10.1038/sj.ejhg.5201113

Keywords: screening; ethics; public health; quality assessment; regulation; Europe

\section{Introduction}

In 1975, genetic screening had been defined as the search in a population for persons possessing certain genotypes

*Correspondence: Prof S Aymé, Hôpital Broussais, INSERM SC11, 102 rue Didot, F-75014 Paris, France. Tel: + 331565381 37; Fax: + 331565381 38; E-mail: ayme@orpha.net

${ }^{4}$ Current address: Faculty of Law and Department of Social and Preventive Medicine, University of Montreal, Montreal, Canada. that (1) are already associated with disease or predispose to disease, (2) may lead to disease in their descendants, or (3) produce other variations not known to be associated with disease. ${ }^{1}$ Today, genetic screening may be defined as any kind of test performed for the systematic early detection or exclusion of a hereditary disease, the predisposition to such a disease or to determine whether a person carries a predisposition that may produce a hereditary disease in offspring. With better knowledge of the genetics 
of various diseases and a larger capacity of genetic technology, genetic screening at an early stage for an increasing number of medical disorders is possible. Justifications offered in support of genetic screening include early diagnosis and treatment and reproductive decisions.

Genetic screening refers to explicit and systematic programmes directed either at whole populations of asymptomatic individuals or at subpopulations in which risk is known to be increased. Genetic screening has to be distinguished from genetic testing because the implications are different. Genetic testing is carried out on patients who for whatever reason have taken the initiative and seek professional advice. In genetic screening, tests may be seen to be imposed on individuals. The ethical dilemmas are magnified and the responsibilities for the physician correspondingly greater. ${ }^{2}$ The genetic nature of a disorder results in risk implications to family members of the person screened, even though they may not be, nor perhaps wish to be, included in the screening programme. Genetic screening is also distinguished from other forms of screening because it does not necessarily lead to the prevention or treatment of diseases.

The possible detrimental effects of genetic screening include fear of undue pressure on individual choice, or social stigmatization of persons who might say no to an offer of genetic screening. Consequently, the threat of misuse of genetic screening requires safeguards. Criteria for introducing genetic screening programmes should include ethical considerations as well as public health ones. Genetic screening goals and the target population must be well defined; laboratory quality control stringent, with limits of results clearly delineated; the confidentiality of the information protected by authorities; procedures to protect individual and family privacy established in advance; participation voluntary; genetic counselling offered and educational programs in place; and long-term outcomes monitored and evaluated. The availability of genetic tests at low cost in some countries already seems to be leading to the systematic offer of screening tests without the appropriate medical environment for providing information prior to testing as well as comprehensively explaining the results afterwards. The risk is perhaps low in most European countries where access to health care is organized as public service, but there remains the problem of controlling the importation of tests that could be sold outside of the health system. There is, therefore, a need to introduce effective and acceptable safeguards, standards and procedures relating to informed consent, counselling and confidentiality, and to the risk of discrimination in employment and insurance.

This document does not discuss genetic screening programmes already well-implemented, but focuses on the issues surrounding potential screening programmes that require further discussion before their introduction.
This document aims to increase, among the health-care professions and health policy-makers, awareness of the potential screening programmes as an issue of increasing concern to public health.

\section{Methods}

The methods used for analyzing the principles, the techniques, the practices, and the policies of genetic screening were primarily the review of the existing professional guidelines, regulatory frameworks and other documents related to population genetic screening programmes in Europe. Then, with the help of the existing guidelines and a review of literature, the method was to examine questions that need debate, with respect to different types of genetic screening before and after birth. Screening for conditions such as cystic fibrosis (CF), Duchenne muscular dystrophy (DMD), familial hypercholesterolemia, fragile $\mathrm{X}$ syndrome, hemochromatosis, and cancer susceptibility was discussed. Special issues related to genetic screening were also examined, such as informed consent, family aspects, commercialization, the players on the scene and monitoring genetic screening programmes. Afterwards, these questions were debated during an international workshop organized by the European Society of Human Genetics Public and Professional Policy Committee in Amsterdam, the Netherlands, November, 19-20, 1999.

The purpose of the workshop was to identify, from a professional viewpoint, the most important/pressing/burning ethical issues relating to population genetic screening programmes in Europe. The issues were discussed throughout the following four sessions: (1) general aspects of genetic screening; (2) programmes before birth; (3) programmes after birth; and (4) ethical issues raised by such programmes.

A group of 51 experts from 15 European countries was invited. These experts were representatives of the seven following sectors:

1. Medical genetics

2. Human genetics societies

3. Ethical, legal and social issues

4. Support groups

5. Biotechnology/pharmaceutics

6. Insurance/employment

7. European union institutions

A first background document was used for the discussions during the workshop. A second document, including discussions of the workshop, was sent for comments to representatives of the human genetic societies and European experts in the field of population genetic screening programmes, as well as to all ESHG members. This document was also put on the ESHG 
website (www.eshg.org) for public consultation and discussion. The final document was approved by the ESHG board.

Recommendations were developed by the ESHG-PPPC and they were endorsed at the Amsterdam ESHG annual meeting in May 2000 by the ESHG members; they have been also endorsed by the Board of Directors of the American Society of Human Genetics. The recommendations have been published in the Europ J Hum Genet (vol. 8, no. 9, September 2000).

\section{Review of literature}

\section{General principles for genetic screening}

Both at the national and supranational levels, guidelines have been elaborated with a view to the developments in genetic screening and the ethical issues raised by it. All these documents deal with the question as to which requirements apply to screening programmes. In any genetic screening programme, guidelines should be established governing its aim, limitations, scope, and ethical aspects, as well as the storage and registration of data or material, the need for follow-up (including social consequences), and the risk of side effects. The two most frequently cited objectives of genetic screening are to reduce the prevalence of the disorder and to inform individuals and couples at risk about their reproductive choices. Particular attention is being paid to the rights of participants in terms of informed consent, confidentiality, and data protection.

WHO Guidelines for screening for disease In 1968, the World Health Organization enumerated the following 10 guidelines that should be considered prior to the implementation of a screening programme:

- Is the disease an important health problem?

- Is there a recognizable latent or early symptomatic stage?

- Do we know the natural history of disease?

- Is there an effective treatment for patients with recognized disease?

- Is there a suitable test that will identify the disease in its early stages?

- Is the test acceptable to the population?

- Do we agree on who treats the disease?

- Are facilities for diagnosis and treatment available?

- Case finding should be ongoing.

- The cost of case finding (including diagnosis and treatment) should be economically balanced in relation to possible expenditures on medical care as a whole.

The authors stated a fundamental presumption, namely, the requirement that the course of the disease must be modifiable or preventable by early detection and treatment or intervention. ${ }^{3}$ A great concern was the most appropriate time to screen to effect the best outcome for the individual along with a concomitant sensitivity towards issues involving communication, consent and labelling. The extend to which a disease was an important health problem varied according to the number of cases of the disorder and its severity. The authors considered that the implications of disease burden should be viewed both from the population health perspective and that of the individual. What constituted a sufficiently large burden to justify screening would depend on the cost of screening and follow-up.

The 1968 WHO guidelines were given before prenatal diagnosis and carrier testing was possible. Therefore, they apply only to a subset of screening today. ${ }^{4}$ In 1998, the WHO has reiterated that the main objective of genetic screening is to prevent disease or secure early diagnosis and treatment. They have reaffirmed the voluntary use of genetic screening and proposed the following guidelines:

- Genetic screening should be voluntary, not mandatory;

- Genetic screening should be preceded by adequate information about the purpose and possible outcomes of the screen or test and potential choices to be made;

- Anonymous screening for epidemiological purposes may be conducted after notification of the population to be screened;

- Results should not be disclosed to employers, insurers, schools, or others without the individual's consent, in order to avoid possible discrimination;

- In rare cases where disclosure may be in the best interests of the individual or of public safety, the health provider may work with the individual towards a decision by him/her;

- Test results should be followed by genetic counselling, particularly when they are unfavorable;

- If treatment or prevention exists or is available, this should be offered with a minimum of delay;

- Newborn screening should be mandatory and free of charge if early diagnosis and treatment will benefit the newborn.

Council of Europe recommendations The Council of Europe has also adopted recommendations on genetic screening between 1990 and 1994. In these recommendations, genetic screening is defined as 'a test applied to a defined group of persons in order to identify an early stage, a preliminary stage, a risk factor or a combination of risk factors of a disease'. The aim of screening is 'to cure the disease or prevent or delay its progression or onset by early intervention'. The Council points out that 'because there are differences in health needs and health services, as well as in ethical values and in legal norms and rules between countries, the decision to implement a screening programme should be taken in cooperation with the medical profession by each country'. In 1997, the Convention for the Protection of Human Rights and Dignity of the Human 
Being with Regard to the Application of Biology and Medicine has endorsed these recommendations.

The Committee of Ministers of the Council of Europe thinks that the public generally recognizes the benefits and the potential usefulness of genetic screening for individuals, for families, and for the population as a whole, but it says that there is an accompanying anxiety that genetic screening arouses. Its recommendations to allay any future unease include: informing the public in advance; educating professionals to provide quality services; offering appropriate, nondirective, counselling; providing equality of access; respecting the self-determination of those tested; making screening noncompulsory; and denying insurers the right to require testing or to seek the results of previous tests. In the area of data protection and professional secrecy, genetic information for diagnosis or prevention of disease and for research should be stored separately from other personal records. In addition, those handling the information should be bound by professional rules of confidentiality and legislative rules, and any unexpected findings should be given only to the person tested.

The Nuffield Council on Bioethics, genetic screening: ethical issues The improvement of the health of persons who suffer from genetic disorders should be the first aim of genetic screening: 'the benefits of screening should be seen as enabling individuals to take account of the information for their own lives and empowering prospective parents to make informed choices about having children'. The report drew on experience of screening for serious diseases such as CF and sickle cell anemia while recognizing that it is difficult to define which disease can be considered serious. The report examines other issues such as voluntariness, informed consent, counselling, confidentiality, and the possible use of genetic information by insurers or employers. The Nuffield Council on Bioethics considers that genetic research differs from many medical advances because of the speed of its development, its effect on individuals, families and the general society, and also the 'fear it arouses that it may be interfering with the basis of life itself'. In other respects, current genetic screening programmes should not result in any stigmatisation or compulsion. The Council feels that family members have a legitimate and strong interest in knowing the results of the person tested; when disclosure of screening results to other family members is vital, the Nuffield Council suggests persuasion as a strategy to minimize potential harmful consequences to family members. ${ }^{5}$

The report called for the establishment of a central coordinating body to monitor genetic screening programmes once they are in place to make sure that they are: (1) following proper standards and criteria in providing information to people; (2) not introducing an element of compulsion; (3) protecting the data; (4) following any guidelines and rules that have developed in relation to the release of data for insurance. The coordinating body should also assess and recommend to government the value of establishing a screening programme before its inception. The conclusions of the report have been widely endorsed.

The Danish Council of ethics and mapping of the human genome The Danish Council of Ethics defines genetic screening as the study of the occurrence of a specific gene or chromosome complement in a population or population group'. The motives for introducing screening programmes are that an individual has a right to expect community-based help like 'offering information that enhances choice and scope for action'. The duty to help is interpreted in terms of autonomy and self-determination, rather than promoting the health of the individual or the genetic health of the population. Counselling must be available and nondirective.

The Danish Council of Ethics views genetic information as different from other private information since it reveals knowledge not only about an individual, but also the individual's relatives, and because analyses will provide comprehensive information about both individuals and population groups. The Council says that screening provides information useful either to the individual or to public health officials, but this information is not concerned with treatment. From a public health point of view, testing may prevent costly treatment of a disease, protect third parties, and give the person the option of treatment. However, from the individual's point of view, there may be ambivalence about the possibility of a relative's potential disease.

The report draws attention to the danger of stigmatization in cases where some minority ethnic groups have a higher frequency of a particular gene. The report recognizes the possibility that termination on the grounds of genetic disorder might lead to decreased acceptance of such disorders in the population. But the Danish Council does not specify the role of public authorities concerning genetic screening within the health-care system.

\footnotetext{
The Health Council of the Netherlands: Committee Genetic Screening, Genetic Screening The Dutch Health Council defines genetic screening as 'any kind of test performed for the systematic early detection or exclusion of a hereditary disease, the predisposition to such a disease or to determine whether a person carries a predisposition that may produce a hereditary disease in offspring'. The Council states that 'the programme for the early detection and treatment of diseases should involve an important health problem'. However, according to the Council, 'it is up to the individual and parents to determine whether a condition is serious enough to enter a screening programme'; genetic screening aims 'to enable people to achieve greater autonomy and to decide upon a course of
} 
action that is acceptable to them'. In other respects, 'a genetic test offered to all may advance equal access to health services, but an offer to a group with an increased risk can be justified'.

The Dutch report remarks that 'an invitation to undergo screening will confront people with risks of which they are not fully aware and this may cause anxiety'; possible stigmatization of participants may also influence compliance. Because of that, 'voluntary participation based on well-understood information is an absolute requirement and there must be safeguards for free individual choice during the whole screening process'. Counselling is also considered important.

Regarding disclosure of screening results to others, the Dutch Council refers to the 1989 report 'Heredity: science and society' for its stance on disclosure of information to others: 'consent of the person tested is needed for disclosure to relatives. If this consent is refused and if the screenee cannot be motivated to give consent, the counsellor or physician is not allowed to disclose the information'.

An authorization must be obtained for screening for serious diseases and abnormalities that cannot be treated or prevented. This authorization will be rejected if the anticipated benefits are outweighed by the attendant risks to the health of the persons examined.

\section{Genetic screening programmes}

Although basic requirements for a genetic screening programme are prominent in the literature, there is little consensus on which disorders merit screening, which screening test should be used in practice, which elements should be included to estimate the costs or benefits of screening, and how these should be measured, the appropriate level of resourcing, or how to resolve conflicts that arise between individual and collective interests. ${ }^{6}$ Other factors seem also affect the use of genetic screening, such as customs of care, education of the public about the results and limitations of genetic testing, or stigmatization and discrimination issues.

Types of genetic screening There are different types of genetic screening: (1) Genetic screening before birth: which includes screening on fetal cells in maternal blood, maternal serum screening, ultrasound screening, screening on fetal cells obtained after amniocentesis or CVS, and preimplantation genetic diagnosis. The major reason for genetic screening before birth is to detect genetic disorders during early pregnancy. Information can be provided to enable couples to consider to terminate or to continue the pregnancy, while the early diagnosis would allow appropriate plans to be made for treatment and follow-up. ${ }^{7}$ (2) Genetic screening after birth: which includes neonatal screening, carrier screening at antenatal clinics, preconceptional carrier screening, cascade screening, school-age screening, and adults screening. Genetic screening after birth has two purposes. First, it can confirm that the person tested either has, or does not have, certain genetic characteristics, with implications for own future health. The second reason for an adult to be tested is to see if their children will be at risk.

Whatever type of genetic screening, the importance of educating individuals about their options is very important. Adequate understanding of the disease and reproductive options are critical to informed decision-making. Because of the combination of benefit and harm in all procedures, the individuals being screened must receive full and accurate information about the procedure and give their informed consent. It has been argued that when uncertainty exists, it should be discussed and advice should be explicitly supported by the best available evidence. ${ }^{8}$ In UK, the General Medical council's guidance on seeking patients' consent makes it clear that physicians must make sure that patients are provided with all the information they want or ought to have to make a properly informed decision. ${ }^{9}$ Since there is uncertainty about how much information needs to be given before screening, quality of information and access to full information for those who wish it is very important.

Before birth Genetic screening has largely been introduced into prenatal care. ${ }^{10}$ Prenatal screening focus on the early detection of serious disorders. Prenatal screening attempts to identify fetuses at an increased risk of anomalies based on family history or increased maternal age or screening tests such as maternal serum testing and ultrasound. Prenatal screening usually is a first step that may lead to prenatal diagnosis. There are three major reasons for prenatal diagnosis: (1) intrauterine therapy which exists for some conditions; (2) to have an option to terminate the pregnancy if that is what the parents wish to do, and (3) the parents know the health status of the foetus. ${ }^{11}$

Methods of prenatal diagnosis must be safe and effective. The standard method for diagnosis in the high risk group is amniocentesis at about 15 weeks of pregnancy. The result of the karyotype is rarely incorrect. The fetal loss rate attributed to amniocentesis has been estimated at 0.3$0.5 \%$. Before 15 weeks of pregnancy, a transabdominal or transcervical chorionic villus sampling may be performed, but the diagnostic accuracy is lower than that of amniocentesis and the fetal loss rate depends on the expertise of the operator, and so may be slightly higher when the procedure is not limited to expert centres. ${ }^{12}$

(1) Screening on fetal cells in maternal blood: Fetal cells can be identified in the maternal circulation and techniques such as fluorescent or magnetic in situ hybridization can be used to identify aneuploidies, including Klinefelter syndrome, Down's syndrome and trisomy 13 and 18. It has been suggested that cells can be adequately sampled 
between 10 and 18 weeks of pregnancy. Screening on fetal cells in maternal blood may in the future be of value in screening. A study showed that examination of fetal cells from maternal blood may provide a noninvasive prenatal diagnostic test for trisomy 21 with the potential of identifying about $60 \%$ of affected pregnancies. ${ }^{13}$

Screening on fetal cells in maternal blood is in its early stages. Currently, it cannot be of practical use before several requirements are met, namely: (1) adequate enrichment of fetal cells in the sample; (2) unequivocal distinction between fetal and maternal cells; (3) accurate methods for single cell diagnosis; and (4) acceptable cost. ${ }^{12}$ Given the rarity of the most successful fetal cells (nucleated fetal red cells) in maternal blood, sophisticated techniques are required to obtain an adequate sample of these cells for analysis. The techniques available do not have the performance, simplicity, or economy needed to replace existing methods yet. ${ }^{14}$

(2) Maternal serum screening: In 1972 raised amniotic fluid alpha-fetoprotein (AFP) was shown to be associated with open neural tube defect pregnancies. ${ }^{15}$ In 1983, it was shown that low maternal serum AFP was associated with Down's syndrome. This association was found to be independent of maternal age. Then, raised maternal serum human chorionic gonadotrophin (hCG), and low unconjugated oestriol (uE3) were found to be markers of Down's syndrome. These two markers, together with AFP and maternal age, formed the basis of the 'triple test'. In 1987, the American Society of Human Genetics (ASHG) published a statement about issues that affect maternal serum AFP programmes and quality control for laboratories performing maternal serum and amniotic fluid AFP assays. The ASHG emphasized the following points: (1) potential applications of MSAFP were still unfolding. Therefore, ongoing educational programmes were needed for providers of obstetrical care and for patients. Counselling of patients regarding MSAFP should begin early in pregnancy so that their decision is informed and unhurried; (2) providers should educate patients about the MSAFP potential and allow patients to make decisions concerning participation in screening and in consequent steps in the management of the pregnancies; and (3) MSAFP screening should only be undertaken in conjunction with a competent laboratory.

The three biochemical markers have been widely adopted and used to detect neural-tube defects and chromosomal aberrations. Triple test determines the probability (with 85-90\% accuracy) of the presence of anencephaly or spina bifida or (with 60-65\% accuracy) of the presence of fetal Down syndrome. Strategies for a more efficient Down's syndrome screening include the use of markers such as dimeric inhibin-A, hyperglycosylated hCG and beta-core fragment of hCG, as well as first-trimester screening, particularly with PAPP-A and free beta-hCG. ${ }^{16} \mathrm{~A}$ number of papers have compared the effectiveness of different combinations of these markers. Some recommend MSAFP, total hCG and uE3, while others advocate MSAFP and free beta-hCG. In 1997, triple test was considered as being the most efficient method of screening based on the information available and the most equitable, ensuring that women with the highest risk are offered an amniocentesis. ${ }^{12}$ Hyperglycosylated hCG has been considered as being an effective replacement for hCG and may be used as a screening test for aneuploid pregnancies. ${ }^{17}$

The introduction of the triple test screening has raised the problem of proper counselling expectant mothers before and after the test. The inability of health professionals ordering the test of explaining abnormal triple test outcomes correctly has been documented in several studies. ${ }^{18,19}$ More efforts have been recommended in order to reduce unreasonable maternal anxiety by adequate counselling. ${ }^{20}$

(3) Ultrasound screening: Ultrasonographic assessment of the fetus is a routinely used screening tool for the presence of congenital anomalies. Most major structural malformations can be detected. ${ }^{21,22}$ It has been argued that there is no evidence for a harmful effect of diagnostic obstetric ultrasound. The main limitations of the technique are its dependence on the skill of the operator and the quality of the equipment. Its main risk is misinterpretation of the image, leading to failure to detect abnormalities or to abortion of a healthy fetus. In European countries, detection rate of severe congenital anomalies varies from 28 to $60 \%$ according to the skill of the operators. ${ }^{23}$

Fetal nuchal-translucency thickness, measured by ultrasonography at 10-14 weeks of gestation is a marker of risk of chromosomal anomaly. Selection of the high-risk group of trisomy 21 for invasive testing by this method and by well-trained professionals allows the detection of about $80 \%$ of affected pregnancies. ${ }^{24}$ Other results have shown that screening for fetal aneuploidy by nuchal-translucency measurement can be effective as part of routine antenatal care in an unselected population. ${ }^{25,26}$ At the population level, effectiveness should increase by enhancing education and training and the systematic referral for fetal anomalies screening to accredited laboratories. In addition to the increased nuchal translucency association with aneuploidy, multiple studies have now identified increased nuchal translucency as a nonspecific marker of a wide range of fetal structural abnormalities, to include congenital diaphragmatic hernia, cardiac defects, and various genetic syndromes. However, further evaluation is required to assess the role of nuchal-translucency screening in the general population when measurements are made by untrained professionals. ${ }^{27,28}$

The advance of the capacities of ultrasound screening raises both ethical and psychological issues. The primary goal of ultrasound screening was to observe the development of the pregnancy to the best of mother and child and for birth management, but with increasing quality of the 
technique and experience of the investigators abnormalities of the fetus became evident. Consequently, the difficulties of counselling expecting mothers appear: most women being offered an ultrasound scanning are at low risk of fetal abnormality and they believe that the test is designed above all to confirm gestational age, not to detect a range of abnormalities. There are important differences in the information provided before scanning, in the types of tests available, and in the amount of counselling provided before, during, and after such tests. Research suggests that many women are not told beforehand of the first scan's potential to detect fetal anomalies. ${ }^{29}$ Many women whose pregnancies may have naturally ended in spontaneous prenatal loss are thus being faced with having to make an active and quick decision about whether to continue with their pregnancy. There is also no firm evidence that early termination is psychologically advantageous to women who undergo this procedure for fetal abnormalities. ${ }^{29}$ For the ultrasound operators, since increased translucency may also be associated with other chromosomal abnormalities, cardiac abnormalities and a number of genetic syndromes, this may create a dilemma if the woman has declined nuchal assessment. Several recommendations have been made to improve clinical practice in prenatal testing. Staff training in providing clear and accurate presentation of all available information to all women before ultrasound screening is paramount to ensure that consent is truly informed. Careful consideration may need to be given to the way psychological support is offered in order to improve uptake of counselling services. ${ }^{29}$

(4) Screening on fetal cells obtained by amniocentesis or CVS: Prenatal diagnosis for chromosomal disorders is now widely offered to high-risk groups, either defined on the maternal age or using risk calculations based on serum marker screening test results or measurement of the nuchal-translucency, or a combination of the three. Most women at risk of carrying an affected fetus with a chromosomal disorder are offered an invasive prenatal diagnostic test. Those tests, amniocentesis and chorionic villus sampling (CVS) carry a risk of procedure-related fetal loss. Some professionals feel justified to offer all the available diagnostic tests to make an optimal use of the fetal cell sampling. ${ }^{30}$ The same approach apply to fetal cells obtained for the prenatal diagnosis of a Mendelian disorder: a systematic karyotype is often also offered, representing a systematic screening of chromosomal anomalies. The history of genetic disorders in different populations is an important consideration in deciding which disorder to screen.

(5) Preimplantation genetic screening: Preimplantation genetic diagnosis (PGD) represents an additional prenatal service for couples at high genetic risk and it may become more widespread in the future. Since the first births were reported using preimplantation genetic diagnosis, ${ }^{31}$ it is now performed in many countries.
PGD involves testing one or two cells taken from a recent embryo of eight cells produced by in vitro fertilization, and selective transfer of embryos. This procedure is applied mainly for X-linked disease but also for a variety of other chromosomal and single-gene defects. ${ }^{32}$ The advantage of PGD Is that it excludes the necessity of a therapeutic abortion. Disadvantages are the requirement of in vitro fertilization, which has only a $15-20 \%$ pregnancy rate, and the experimental nature of the procedure. In fact, preimplantation genetic diagnosis requires stimulation of ovulation, which can have serious side effects. Egg collection is an invasive procedure, implantation somewhat less so and the success rate is still low. It is also difficult to ensure accurate diagnosis on one or two cells and the risk of misdiagnosis is higher than in other prenatal diagnostic procedures. ${ }^{33,34}$ PGD is offered as a very early form of prenatal diagnosis to women who are at high risk (25-50\%) for having a baby with an inherited condition and who do not wish to face the possibility of pregnancy termination. It is not feasible to test routinely women at lower risks, since the means of establishing a pregnancy is with the help of IVF, but women who conceive with assisted reproductive technologies could be offered a preimplantation genetic test. For instance, PGD could be used as a screening method for chromosomal disorders in all preimplantation embryos to avoid ill children or to improve the rate of pregnancies in the infertility treatment.

Some consider that PGD raises issues of genetic engineering and sex selection. To develop uniform guidelines for practitioners and to promote appropriate application of PGD, the European Society for Human Reproduction and Embryology PGD Consortium has been created in 1997. The main goal is to standardize the practice of PGD by promoting the exchange of all types of data. More specifically, sex selection through PGD for nonmedical reasons should not be encouraged as such, as per the recommendations of The Ethics Committee of the American Society of Reproductive Medicine. ${ }^{35}$ It has been suggested that the European Society for Human Reproduction and Embryology PGD Consortium plays an important role within Europe to help shape any legislation that is introduced to regulate PGD and limit its application.

After birth There are several types of screening after birth. ${ }^{36}$ The first widespread screening was for the detection of phenylketonuria in newborns. Sickle cell disease screening as well as screening for hypothyroidism and congenital adrenal hyperplasia have been added to the neonatal screening menu. The inclusion of screening for conditions such as CF and DMD are currently being discussed throughout the countries. For example, some have questioned whether the neonatal detection of CF affects its clinical course. ${ }^{37}$ But even if there is no effective treatment for this and other genetic diseases detectable at 
birth, such as DMD, neonatal screening has sometimes been recommended so that parents can receive genetic counselling about future pregnancies.

Evolving knowledge of the genetic basis of a variety of common diseases has created possibilities for presymptomatic detection of late-onset diseases such as familial hypercholesterolemia and hemochromatosis. Screening for late-onset diseases at birth, although increasingly possible, has never been recommended, because preventive treatments often do not exist or, if available, are best carried out later in life. ${ }^{38}$ Genetic counselling of parents regarding the risk of a disease in a child that manifests itself many decades later is rarely requested or considered. ${ }^{37}$ Screening for late-onset diseases raises complex ethical issues with regard to informed consent, privacy of genetic information and confidentiality of test results.

In addition to screening newborns, there are other strategies for identifying genetic disorders. Screening for heterozygous carriers of autosomal recessive diseases is aimed at identifying carriers who are at risk of having an affected child if the other parent is also a carrier. Such screening can be conducted before pregnancy in order to allow a wide choice of reproductive options, including avoidance of marriage to another carrier, having no children, or the use of a sperm donor, in addition to antenatal diagnosis with elective termination of pregnancy or accepting the risk, and PGD.

For instance, carrier screening programmes for hemoglobinopathies have been in place in several countries for over 20 years; these programmes have been very effective, as indicated by increasing knowledge on thalassemia and uptake of prenatal diagnosis by the target population. ${ }^{39}$ (For this reason, it has been decided that the issue of screening for hemoglobinopathies will not be addressed in the present document.)

(1) Neonatal screening for CF: CF is the most common lethal inherited metabolic disorder in white population. The prevalence is approximately 1 in 2500 live births in populations of Western European origin. CF is characterized by severe respiratory problems and inadequate pancreatic function, caused by accumulation of sticky mucus. In total, $10-15 \%$ of newborns with CF require medical intervention to resolve meconium plugs. Most men with CF are sterile. There is no cure, but improved treatment in recent years has increased the average life expectancy to about 30 years. ${ }^{40}$ Intense respiratory management by inhalants, antibiotics, physical therapy, and enzyme supplements improves survival. Knowledge of the gene defect has opened up new lines of research, which may in time result in quite new forms of treatment. Clinical studies on anti-inflammatory agents are underway.

$\mathrm{CF}$ is caused by mutation of the gene encoding the CF transmembrane conductance regulator (CFTR). More than 1000 CFTR gene mutations have been identified; few mutations account for a large proportion of mutations in selected populations. Prevalence of different mutations varies according to the ethnic composition of populations. There is no simple correlation between the nature of the mutation and the severity of lung disease, although some mutations result consistently in milder pancreatic disease. $^{41}$

Neonatal screening for $\mathrm{CF}$ is available through dried blood analysis for immunoreactive trypsinogen (IRT). Some recommend combination of IRT, sweat test and genetic mutation analysis for primary or recall testing. The overall sensitivity of neonatal screening is about $85-90 \%$. The rationale for neonatal screening for CF is that very early detection and treatment may improve clinical outcomes for children with $\mathrm{CF}^{42}$ but the evidence for this is currently controversial; the ability of screening to alter long-term prognosis has not been conclusively proven. ${ }^{43-47}$ Nevertheless, there is some circumstantial evidence favoring a benefit: screening spares parents the anxiety experienced in the time between the onset of symptoms and diagnosis; screening may also prevent a second affected pregnancy if parents are aware of their genetic status before conceiving another child. An alternative would be to train the pediatricians and the general practitioners about the necessity to test for CF any infant with a failure to thrive. This approach would be likely to pick up most of the cases with a significant clinical course.

Neonatal screening for CF is currently practised in some countries like in Italy or in the UK in some regions. ${ }^{48}$ In France, it has been asked that health authorities implement a 3-year pilot state-based neonatal screening programme (Farriaux 1999). However, it has been suggested that more research should be carried out on the benefits of neonatal screening. Recommendations for future research include: (1) more research on psychological and medical consequences for carrier detection in neonatal screening; (2) neonatal screening programmes to undertake RCTs of specific early treatments; and (3) audit procedures to ensure that parents give informed consent to neonatal screening. ${ }^{43,49,50}$

(2) Neonatal screening for DMD: DMD is characterized by a rapidly progressive muscle weakness. This is the most frequent X-linked childhood disorder. The disease is frequent in all world populations. Prevalence at birth for DMD is $\sim 1: 3500$ male births worldwide and $\sim 1: 5000$ in developed countries that provide genetic counselling. In $\sim 70 \%$ of the cases, female subjects are carriers of the disease and only rarely develop symptoms. About 30\% of reported cases are new mutations. The age at which clinical symptoms of DMD are first noted is usually between 2 and 5 years. In all affected youngsters the disease progresses steadily with no remissions. The lifespan is $\sim 20$ years. There is no known treatment of DMD. Treatment is palliative (individualized physical therapy), aimed at managing the symptoms in an effort to optimize the 
quality of life. Assisted ventilation may improve respiratory mechanics and prolong the lifespan.

The dystrophin gene was cloned in 1986. Three different tests are performed to diagnose DMD: (1) creatine kinase (CK) test; (2) muscle biopsy; and (3) DNA testing. ${ }^{51}$ Until recently, a diagnosis of DMD was established markedly on the basis of the clinical picture, the course of the disease, the increased activity of the enzyme CK and histological findings. DNA testing coupled with analysis of the protein involved has made the distinction between DMD and Becker muscular dystrophy possible. Genetic counselling and prenatal diagnosis have to some extent lowered the prevalence of DMD. The disease can also be detected soon after birth in babies where there is a positive family history.

Even if testing at birth is controversial since there is no advantage for newborns, which is a critical prerequisite for screening, neonatal screening has been recommended so that parents can receive genetic counselling about future pregnancies. ${ }^{52}$ Parents can be advised about the genetic risk of recurrence, information that otherwise might not be available until a diagnosis is made at a later date. ${ }^{37,53,54}$

(3) Screening for fragile X syndrome: Fragile X syndrome is the most common cause of mental retardation from a single gene defect, transmitted in an X-linked semidominant fashion. ${ }^{55}$ The latest population prevalence figures are about 0.25 per 1000 male subjects and 0.12 per 1000 female subjects. About $6 \%$ of institutionalized individuals with mental handicap have the syndrome. The major features are learning disability of varying severity, behavioral problems such as hyperactivity and autistic tendencies, and physical characteristics. Although fragile $\mathrm{X}$ syndrome is not curable, there are a number of medical, educational, psychological and social interventions that can improve the symptoms. However, this syndrome is still not recognized and underdiagnosed: many at-risk families are not aware of their risk and there is no reliable estimate of the prevalence of women who are carriers of fragile X premutations. ${ }^{56}$

The responsible gene, FMR-1, was identified in 1991 and includes a trinucleotide repeat sequence. The mutation is characterized by hyperexpansion of the repeat sequence leading to downregulation of the gene. In male subjects, an allele with repeat size in excess of 200, termed a full mutation (FM), is always associated with the affected phenotype, whereas in female subjects only half are affected. Individuals with alleles having repeat size in the range 55-199 are unaffected, but in female subjects the sequence is heritably unstable so that it is at high risk of expansion to an FM in offspring. This allele is known as a premutation (PM) to contrast it with the FM found in the affected individual. The number of CGG repeats in a PM is potentially unstable and can increase into the FM range in a child that inherits the affected chromosome from its mother. The chances of a PM in a mother expanding to an FM in her child have been estimated at about $10 \%$ in the general population and about $60-80 \%$ in known fragile $\mathrm{X}$ families. In contrast to the potential instability of a PM transmitted from the mother, a PM transmitted from the father does not expand to an FM in his daughters. ${ }^{57}$

Among the screening tests, cytogenetic methods are unsuitable for screening purposes. Southern blotting of genomic DNA can be used but is inaccurate in measuring the size of small PMs, there is a long laboratory turnaround time, and it is relatively expensive. The best protocol is to amplify the DNA using polymerase chain reaction on all samples, and when there is a possible failure to amplify, a Southern blot. ${ }^{57}$ A procedure that uses the automatic laser fluorescent (ALF) sequencing apparatus and reduces the number of samples that need to be analyzed by Southern blotting appears suitable for large scales screening of female subjects at-risk of carriers for fragile X syndrome. ${ }^{58}$

A number of possible options for genetic screening for fragile X mutations have been discussed. They fall into two groups: screening to detect women who have the FM or PM alleles and screening to detect affected individuals. In the first group, possible screening strategies are: cascade screening, antenatal and preconceptional screening. Pilot programmes have reported that cascade screening has been well-received and has offered reproductive choice to families affected by this disease. In Australia, it has been reported that the birth prevalence of fragile $\mathrm{X}$ syndrome has decreased from 1 in 4000 male subjects to 1 in 10000, ${ }^{59}$ while in the Netherlands, a simulation model for studying the consequences of cascade testing for fragile $\mathrm{X}$ syndrome shows that cascade testing is effective in detecting carriers only if several generations are tested. ${ }^{55}$ According to the authors, to detect $90 \%$ of all PM and FM carriers at least eight consecutive generations need to be tested. In UK, cascade screening has been recommended, although there should be a national audit of current practice. ${ }^{57}$ Antenatal screening also provides an effective way of identifying carriers. It is well accepted and has a favorable cost-savings balance but put the couples in the situation of having to make a decision under time pressure. In Finland, it has been suggested to incorporate this screening strategy as a routine part of antenatal care in general practice. ${ }^{60}$ With this approach, it is possible to reach the largest possible population and offer this option to virtually all pregnant females. ${ }^{58}$ Preconceptional screening allows adequate time for genetic counselling and eliminate any adverse consequences that might result from receiving distressing news during pregnancy. It also offers at-risk couples more reproductive choices. However, it has been argued that this would be difficult to practice, since most women carriers of fragile X syndrome are not well informed of their risk. ${ }^{57,60}$

In the second group of options for genetic screening for fragile $X$ syndrome, that is to say screening to detect affected individuals, the screening approaches (neonatal and pediatric screening in high-risk groups) raise questions on the justification of diagnostic testing in individuals who 
are suspected as having the syndrome. As there is no cure, there may be little value in accurate diagnosis. The debate against screening has centered around the potential stigmatization of fragile $\mathrm{X}$ syndrome patients. It has been argued, however, that accurate diagnosis allows appropriate treatment to be offered for the behavioral and educational difficulties associated with the syndrome. In addition, if fragile $\mathrm{X}$ syndrome is diagnosed, screening in other family members can allow them to make informed reproductive decisions on the basis of their genetic status. $^{57}$

Before implementing a population-based screening programme, studies should be carried out to establish a reliable prevalence of the disease as well as to assess the feasibility of routine screening and the emotional and social consequences of being identified as carrying a premutation. ${ }^{57}$ In USA, the American College of Medical Genetics (ACMG) ${ }^{61}$ recommended in 1994 that diagnostic testing should be offered for individuals with symptoms suggestive of fragile $\mathrm{X}$ syndrome, individuals who have a family history of learning disability and who seek reproductive counselling, and pregnant women who are known to have a premutation. The report did not recommend population screening for fragile $X$ mutations except in the context of research. Cascade screening is already conducted in many regions, but not on a systematic basis.

(4) Screening for familial hypercholesterolemia: Genetic screening for familial hypercholesterolemia may be appropriate since risk of early coronary artery disease (CAD) is considerably increased by the mutation of a single gene. ${ }^{62-64}$ Familial hypercholesterolemia is an autosomal dominant disorder characterized by elevation of serum cholesterol bound to low-density lipoprotein (LDL). Mutations in the LDL-receptor gene on chromosome 19 cause this disorder. Plasma cholesterol is elevated at birth, and cholesterol tends to deposit in the walls of arteries causing atherosclerosis and consequently, cardiovascular disease (heart attack, stroke) potentially fatal in patients after 30 years old. The disease is diagnosed on the grounds of clinical and biological signs, but genetic diagnosis formally identifies the causative factor. One in every two people can be affected in a family where one individual has been identified as having familial hypercholesterolemia due to a mutation of the LDL-receptor gene. Once the diagnosis is established, drug therapy (adapted for each age and case) brings the levels of plasma cholesterol back to normal and may cause atherosclerosis to regress, thus preventing potential cardiovascular complications. The heterozygous patients are generally treated in the same way as patients in the general population with a high cholesterol rate. Curing homozygous patients is more difficult because they express little or no activity from the LDL receptor and they are resistant to most cholesterol-lowering drugs. The prevalence of familial hypercholesterolemia is of $1 / 500$ in Western societies. The homozygous
FH is very rare, occurring with the frequency of about one in a million.

DNA testing is the best way to diagnose familial hypercholesterolemia. ${ }^{65}$ It is appropriate in particular when (1) physical signs or family history are equivocal or absent (important given the increased risk of CAD associated with $\mathrm{FH}$ compared to other hypercholesterolemias) and (2) when there is a family history of premature CAD, especially in immediate family members. ${ }^{62}$ A positive DNA-based test for a mutation is especially useful in children, in whom plasma lipid levels may not be diagnostic. According to the British Hyperlipidaemia Association, selective screening based on a family history of familial hypercholesterolemia or premature coronary artery disease is an appropriate strategy for identifying most children with familial hypercholesterolemia. ${ }^{66}$ Drug treatment of children with $\mathrm{FH}$ is advisable because of the better possibilities to make a definite diagnosis and the early occurrence of coronary heart disease. However, children should not usually be screened before the age of 2 years.

Even if screening for $\mathrm{FH}$ in childhood can help to save lives through preventive treatment and therapeutic interventions, screening of children remains controversial. ${ }^{67} \mathrm{~A}$ pilot study in UK showed that parents' responses to screening vary according to perceptions of the underlying cause of the positive screening test result. When parents perceive the test as detecting raised cholesterol, the condition is perceived as familiar, dietary in origin, controllable and less threatening. When the test is seen as detecting a genetic problem, the condition is perceived as uncontrollable and, hence, more threatening. ${ }^{68}$ Appropriate genetic counselling must accompany risk assessment, genetic testing and screening for familial hypercholesterolemia. ${ }^{69}$

Population-based genetic screening for $\mathrm{FH}$ in not practical because of the large number of mutations causing this disorder. ${ }^{70}$ However, in some populations most cases of FH can be explained by only one or a few mutations. Examples include the Finns, the French Canadians, and the Christian Lebanese. In these populations the frequency of $\mathrm{FH}$ is higher than that generally accepted in Western countries (of one per 500). ${ }^{70}$ As the number of the LDLreceptor mutations increases, the preferential geographical distribution of some of them has become apparent. Geographical associations for LDL-receptor genes have been reported in the west of Scotland and in the Netherlands. $^{71}$

(5) Screening for hemochromatosis: Hemochromatosis is a disorder of iron metabolism that increases iron absorption and results in excessive iron accumulation. Clinical manifestations range from lethargy and abdominal pain to arthropathy, diabetes, hypogonadism, skin pigmentation, cardiomyopathy, and hepatic fibrosis and cirrhosis. There is a high morbidity and mortality associated with 
untreated hemochromatosis. Clinical manifestations appear in the 40th to 50th decade in men, later in women owing to the protective effect of blood loss from menstruation and childbirth. Symptoms of iron overload are occasionally observed in young men and women (by the age of 20 years). Early symptoms are multisystemic and nonspecific. Early diagnosis and treatment before the occurrence of organ damage improves prognosis. ${ }^{72}$ Among symptomatic individuals, iron depletion treatment can improve some, but not all, clinical manifestations. Periodic phlebotomy to remove the excess iron is necessary to threat the condition. For a subject who has no evident tissue or organ damage, the long-term outcome and life expectancy with proper management of the disease equals that for people who do not have iron overload. For a subject who has evident tissue or organ damage, further damage can be halted, but damage already incurred usually cannot be reversed.

Hemochromatosis is the most common genetic disorder in Caucasians. The prevalence is approximately of $1 / 300$ and $1 / 9$ people is a carrier. A candidate gene on chromosome 6, HFE was identified in $1996 .^{73}$ One mutation, $\mathrm{C} 282 \mathrm{Y}$, has been detected in as many as $11 \%$ of northern European white individuals tested. ${ }^{74}$ About $70 \%$ of men and $40 \%$ of women who are homozygous for hemochromatosis develop clinical manifestations at some point in their lives. Heterozygotes are usually asymptomatic. Another mutation, H63D, appears to act synergistically with $\mathrm{C} 282 \mathrm{Y}$ in about $3-5 \%$ of patients with typical hemochromatosis. ${ }^{75}$ It is becoming accepted that subjects should be tested for both $\mathrm{C} 282 \mathrm{Y}$ and $\mathrm{H} 63 \mathrm{D}$ mutations as a proportion of compound heterozygotes do express clinical disease. Among the screening methods, the biochemical screening test, serum transferrin saturation, identifies about $70 \%$ of men and $60 \%$ of women with hemochromatosis at a $0.3 \%$ false-positive rate. DNA-based testing for $\mathrm{C} 282 \mathrm{Y}$ homozygosity identifies about $83 \%$ of individuals with clinically diagnosed hemochromatosis. ${ }^{76}$ The false-positive rate is likely to be very low. Indications for DNA testing include: (1) previous clinical diagnosis of hemochromatosis; (2) positive family history or partner with hemochromatosis, especially if Cys282Tyr positive; (3) elevated transferrin saturation or serum ferritin concentration; (4) unexplained elevation of serum liver enzymes; (5) cirrhosis, liver failure, or hepatocellular carcinoma; 6) diabetes mellitus; and (7) nonspecific compatible symptoms and signs: fatigue, abdominal pain, hepatosplenomegaly, joint pain, cardiac arrhythmia, congestive heart failure, impotence, hypogonadism, hypothyroidism and hyperpigmentation.

Screening for hemochromatosis using transferrin saturation involves relatively modest costs that may be recovered if complications of hemochromatosis can be prevented by early detection and treatment. ${ }^{77}$ The most cost-effective strategies utilizes transferrin saturation for initial screening, followed by DNA testing. ${ }^{78}$ Reduction in the cost of transferrin saturation would lead to a significant reduction in total screening costs. Additional benefits of a screening programme include detection of other iron overload disorders and iron deficiency. However, screening is not commonly conducted as part of routine medical care or check-ups. The available screening tests are imperfect. While they can identify many persons at increased risk for hemochromatosis, the proportion that will develop serious clinical manifestations related to iron overload is not known with certainty and DNA-based tests do not provide a simple resolution to these questions. ${ }^{79,80}$ Before implementing a population screening programme for hemochromatosis, further research is needed for (1) evaluating the penetrance and preventable disease burden, laboratory standardization, and optimal strategies to minimize potential risks of screening for hemochromatosis; and (2) evaluating the benefits and prevention-effectiveness of population-based screening. ${ }^{80-82}$ Moreover, the size of the effect of screening on reducing morbidity and mortality is uncertain, as well as the best age for screening in men and women. $^{83}$

Guidelines and policy development have been published. Some consider that population-based genetic screening for hemochromatosis is not justified at present, due to uncertainties about prevalence and penetrance of HFE mutations and the optimal care of asymptomatic people carrying HFE mutations. Tests for HFE mutations may play a role in confirming the diagnosis of hemochromatosis in persons with elevated serum iron measures, but even this use is limited by uncertainty about genotypephenotype correlations. In addition, use of a genetic screening test raises concerns regarding possible stigmatization and discrimination. ${ }^{80,82,84}$ In France, a report published by the National Agency for Accreditation and Evaluation in Health (ANAES) concludes that it appears premature to propose a systematic screening insofar as there are still numerous medical uncertainties, the economic aspects have not been calculated, and the individual psychological repercussions are difficult to foresee. ${ }^{85} \mathrm{How}$ ever, since hemochromatosis is a real public health problem, certain initiatives should be taken to produce answers to a series of questions. ${ }^{86,87}$ On the other hand, the College of American Pathologists states that in view of the high prevalence in the American population (prevalence varies with ethnic background), the low cost of diagnosis and treatment, the efficacy of treatment if begun early, and, on the other hand, high costs and low success rate of late diagnosis and treatment, systematic screening for hemochromatosis is warranted for all persons over the age of 20 years. The initial screening should be by measurement of serum iron concentration and transferrin saturation. The practice guideline provides a diagnostic algorithm for cases in which the serum transferrin saturation is $60 \%$ or greater. It also provides guidelines for clinical management. ${ }^{88}$ 
(6) Screening for cancer susceptibility: Cancer mortality rates have risen throughout most of this century in developed countries, and a downward trend has just emerged in recent years. Nevertheless, it is predicted that cancer will soon be the leading cause of death among the Westerners. All cancer can be described as due to altered DNA. Many of these mutations will be accumulated during the normal division of somatic cells. However, some people may inherit abnormal genes, which predispose those individuals to high risk of certain malignancies. These individuals can sometimes be identified by having a family history of affected individuals, some of which might have early age of onset or multiple malignancies. Specific genes have been identified as being associated with certain of these malignancies. The hereditary cancers include ovary, breast, colon, endometrium, and to a lesser extent, prostate, skin and pancreas. ${ }^{89}$ Some of these cancerpredisposing genes are highly penetrant with up to $50 \%$ of gene carriers developing the associated malignancy within a 70-year life expectancy. ${ }^{90}$ Molecular testing for the presence of cancer-predisposing genes is available for many of the hereditary cancers. While there is currently no way to correct a mutant gene, early detection and some techniques of chemoprevention are of clinical value. People who fear that they are at high risk and learn that they are not can benefit from the relief of anxiety through the genetic counselling process. ${ }^{91}$

The study of inherited conditions predisposing to cancer has led to major discoveries on the basic mechanisms of carcinogenesis. Those investigations have permitted to discover a new class of cancer genes now named 'suppressor' genes (or antioncogenes), and to demonstrate their implication in the majority of cancer including the sporadic one's. ${ }^{92}$ Those studies have indicated that familial forms of cancer can also result from alterations of a set of genes controlling genomic stability. In clinical practice, the identification of the molecular basis of major forms of inherited predisposition to cancer, has allowed to define those cancer syndromes better. As a consequence, it appears now possible to propose to the at risk individuals, and their families, screening protocols based on precise estimate of their genetic risk. ${ }^{93}$ However, the rapid advances in molecular technology are a direct challenge to the medical community and cancer centers to supply specialized clinical services. Detection and prevention of certain malignancies are impeded because few medical practitioners know of these tests, and because patients fear the emotional consequences of testing. The need for genetic counselling will increase as more families with inherited cancer are identified, more cancer genes are isolated, and genetic analysis becomes more available.

In the USA, the American Society of Clinical Oncology $(\mathrm{ASCO})^{94}$ recommends that cancer predisposition testing be offered only when: (1) the person has a strong family history of cancer or very early age of onset of disease;
(2) the test can be adequately interpreted; and (3) the results will influence the medical management of the patient or family member. ASCO endorses efforts to strengthen regulatory authority over laboratories that provide cancer predisposition tests that will be utilized to inform clinical decisions. These regulatory requirements should include appropriate oversight of the products used in genetic testing, interlaboratory comparisons of reference samples, as well as quality control mechanisms. ASCO endorses all efforts including legislation to prohibit discrimination by insurance companies or employers based on an individual's inherited susceptibility to cancer. Finally, ASCO endorses continued support of patientoriented research to analyze the psychological impact of genetic testing of at-risk populations.

Two other institutional guidelines, in France ${ }^{95}$ and the USA, ${ }^{96,97}$ on follow-up care of individuals at high genetic risk of ovarian cancer have been released. The French committee suggests that it might be prudent to keep attempts at ovarian stimulation to a minimum in cancerprone women who are being treated for infertility, because this procedure may increase the risk of ovarian cancer in this population. ${ }^{98}$ The US task-force does not address this issue. Furthermore, with respect to the tumour marker CA125 antigen the US task-force recommends its use, whereas the French committee suggests that it should be restricted to clinical trials. ${ }^{98}$ Based on expert opinion concerning presumptive benefit, early breast cancer screening is also recommended by the US task-force, as well as endometrial cancer screening. Concerning hereditary nonpolyposis colon cancer, the US task-force states that colonoscopy every $1-3$ years starting at age 25 years is recommended for individuals known to have HNPCC-associated mutations. No recommendation is made for or against prophylactic surgery (oophorectomy, mastectomy, hysterectomy, colectomy); these surgeries are an option for mutation carriers. It is recommended that individuals considering genetic testing be counselled regarding the efficacy of measures to reduce risk and that care for individuals with cancerpredisposing mutations be provided whenever possible within the context of research protocols designed to evaluate clinical outcomes.

No population screening for cancer susceptibility has been recommended. ${ }^{99,100}$ The benefits and limits of testing, and the range of prevention and treatment are different in each hereditary tumor. Further research is needed to continue the analysis of the significance (frequency or penetrance) of mutations of cancer predisposition genes and to make clear the genotype-phenotype and other correlations. ${ }^{99,101}$ Questions remain about the value of monitoring people with inherited susceptibility mutations and the safety and efficacy of pre-emptive interventions. Mechanisms need to be established to ensure that those offered screening give full, informed, autonomous consent and that laboratories involved in 
testing meet quality standards. It also appears that the results of screening for susceptibility genes are likely to be difficult to interpret without considerable input from geneticists and should not generally be available without genetic counselling. The possible negative effects such as stigmatization and insurance/employment disadvantages resulting from such testing should be carefully discussed by a multidisciplinary committee including geneticists before any screening is introduced, and only those conditions in which clear health benefits from interventions can be demonstrated should be screened for. ${ }^{102}$

(7) Carrier screening at antenatal clinics: Carrier screening programmes attempt to detect individuals who carry a disease-related allele in order to inform them about their specific risk and help them make reproductive choices accordingly. Carriers are phenotypically normal and show no signs of the disease, but such individuals would be at risk for having children with the disorder. ${ }^{6}$ Carrier screening for recessive diseases is initiated during pregnancy. If the result is abnormal, tests of the male partner follow. If both partners are carriers, they are informed of the possibility of a test on the fetus. If prenatal testing is performed and shows that the fetus is affected, the parents can decide whether to terminate the pregnancy.

Carrier screening at antenatal clinics has reportedly been well-received. ${ }^{103}$ Although reduction in birth prevalence is not the aim of such a programme, it has been reported that screening for heterozygosity during pregnancy has led to a marked reduction in the frequency of thalassemia major in several Mediterranean countries as well as in the UK and of Tay-Sachs disease among Ashkenazi Jews in the United States and elsewhere; screening for sickle cell carriers is very well accepted, but the uptake of prenatal diagnosis is lower for sickle cell anemia than for thalassemia. ${ }^{37}$ Screening for carriers of CF has been recommended. In 1997, in the USA, the ACMG recommended that couples in which one or both reproductive partners either has CF or has an affected relative should be offered carrier testing and counselling. ${ }^{104}$ The NIH Consensus Statement on Genetic Testing for Cystic Fibrosis ${ }^{50}$ also recommends that genetic testing for $\mathrm{CF}$ be offered to adults with a positive family history of $\mathrm{CF}$, to partners of people with $\mathrm{CF}$, to couples currently planning a pregnancy, and to couples seeking prenatal care. In UK, the introduction of routine antenatal screening for CF has been recommended. ${ }^{43}$ The report suggests that screening should also be available for infertile men and for sperm donors. Testing should be carried out in laboratories with a high throughput of CF tests. Carrier screening at antenatal screening has been proposed also for Fragile $X$ syndrome in Finland and in UK. ${ }^{57,60}$ In UK, carrier screening at antenatal clinics for hemoglobin disorders is standard practice. However, the UK Confidential Enquiry into Counselling for Genetic Disorders has shown the need for a national policy on screening for hemoglobin disorders, aiming to offer prenatal diagnosis in the first trimester in all pregnancies at risk, and including ongoing audit. ${ }^{105}$

For most recessive conditions, we have no consensus as to which specific carrier screening programmes should be carried out. With the progress that is being made in mapping the human genome, public health applications can be developed which will make it possible in the near future to detect carriers of many recessive gene defects. It has been suggested that carrier screening should at least be considered by those women registering for CVS or amniocentesis. $^{60}$

(8) Preconceptional carrier screening: Some autosomal recessive diseases are often restricted to certain ethnic or racial groups, such as the thalassemias, sickle cell anemia, and Tay-Sachs disease. Population screening for heterozygous carriers is aimed at identifying carriers who are at risk of having an affected child if the other parent is also a carrier. In communities where the risk of serious genetic disorder is high, preconceptional carrier screening may be desirable. ${ }^{106,107}$ In fact, preconceptional carrier screening offers at-risk couples more reproductive options, as well as provide sufficient time to discuss these options. Its allows adequate time for genetic counselling and eliminate any possible adverse consequences that might result from receiving distressing news during pregnancy.

However, preconceptional carrier screening is difficult to practice because reaching of the target group is difficult. For example, clinical trials for CF have shown that many adults say they prefer screening before conception but do not see a physician for evaluation before conception and providers find screening more readily accomplished in the setting of a prenatal visit. ${ }^{108}$ To improve preconceptional carrier screening, the organization of adequate facilities to meet the demand for screening and prenatal diagnosis before the beginning of the educational campaign is essential. ${ }^{106,107}$ A continual monitoring of population responses of what the providers have to offer is another factor affecting effectiveness of screening. Involvement of the population has the advantage of preparing efficacious and simple messages but also of avoiding potential adverse effects on carriers and parents, as well as to be responsive to the cultural values and religious beliefs of the target populations. $^{106,107}$ Cascade screening is also appropriate because people learn by experience.

Screening for CF before pregnancy has been proposed. ${ }^{109,110}$ Costs considerations are not an obstacle, on the contrary it has a favorable cost-savings balance. ${ }^{47}$ However, studies have reported that this type of screening presents logistical difficulties and that advantages, such as opportunities for adoption, had not been shown (J Med Screen 1996;3:55). Much attention seems to be required for provision of information at all stages of the screening procedure. ${ }^{43,46}$ In other respects, testing should be carried out in laboratories with a high throughput of CF tests. 
Regional variations A survey made by the EUROSCREEN Group, a Biomed Project of the European Union, shows that there are no genetic screening programmes common to all western European countries. ${ }^{111}$ Neonatal screening for phenylketonuria is routine in all countries except Finland. The age cutoff at which amniocentesis is offered routinely varies between countries. Screening based on maternal age alone tends to be replaced by maternal serum screening. Regional variations seem to be due to genetic disease patterns and to the novelty of genetic services: Finland has a different pattern of genetic disease from the rest of Europe, selective abortion following testing is not legally acceptable in Ireland, and in Germany the subject of the discussion of genetics and biotechnology is controversial. Regional variations also seem to be due to general factors such as a lack of knowledge of genetic disorders, which is seen as a barrier to informed consent and the fact that those giving informed consent may not be those who will be directly involved in the consequences of the test; which is, parents give consent for a young child. In Germany, although an obligatory newborn screening is established for congenital hypothyroidism, galactosemia and phenylketonuria, in Bavaria the parents have to agree and are allowed to refuse from this programme.

\section{Current legislation}

The principles that need protection seems to be the 'right not to know' and the right not to have others know about genetic traits: protection against logically straining effects from predictive genetic information and protection against genetic discrimination and stigmatization. ${ }^{112}$ How then to guarantee these protections? Different forms of protection may each play a part: information and education, scientific measures regarding the quality and relevance of the tests, codes of conduct, regulation through informal or formal law. Concerning the latter, when there is awareness that a development in society, although beneficial in some respects, could be harmful in others in that it may interfere with individuals rights, usually the call for legislation makes itself felt. However, it has been argued that by enacting laws which are designed to resolve only issues of genetic discrimination and stigmatization, there is a chance that other questions will not addressed. ${ }^{112}$ In addition, there is little evidence of consistency between the various national laws and the supranational provisions either do not address the issue directly or do not contain enforceable sanctions. ${ }^{113}$

Ten western European states have enacted legislation or established a procedural regulatory framework that addresses the issues of genetic screening; either by laws explicitly targeted at screening (Austria, France, The Netherlands, Norway) or by laws that have indirectly an impact on the use of genetic screening techniques (Belgium) or by a procedural system of regulation which can adjust to any changes in technology (Germany, Sweden, The United Kingdom) (see Appendix A). The last method of regulation would be unpredictable and uncertain in posing problems for commercial ventures who would prefer to assess the regulatory climate in the mid to long term before they launch a particular product. ${ }^{112}$ Many other stake-holders (insurance companies, employers, patients) claim the freedom to use genotyping and genetic screening without significant legal restrictions. ${ }^{112}$

Although several European countries have prepared legislation relating to particular aspects of genetics (embryo research, genetic screening, use of genetic tests in employment and insurance), it appears that in general, the response would seem cautious: legislation in the field of genetics is hard, such as the pace of developments and the difficulty of assessing their social consequences. Other problems are the similarity or the difference between genetic information and conventional medical information. It has been proposed that the response of the law would be to monitor rather than to ban and self-regulation by guidelines or codes of conduct should be preferred to statutory regulation; at international level, common principles should serve as a common framework for adequate national policies. ${ }^{111}$ Some issues can be regulated at the national level, but international regulations seem to be preferred for several reasons: the development in genetics is an international one, affecting individuals in all countries, which creates a common responsibility concerning possible harmful consequences. Fundamental divergence of national legislation may have adverse effects on international scientific cooperation and the mobility of health professionals and patients across frontiers. For others, international regulation may enlarge the protection and provide further equality. ${ }^{112}$

The tables below list the current legislation, policy statements, or professional guidelines addressing directly and indirectly the issue of genetic screening.

International comparisons: legislation, policy statements, professional guidelines addressing directly the issue of genetic screening

\begin{tabular}{ll}
\hline Instances & Jurisdiction \\
\hline Australia & Human Genetic Society of Australasia, Newborn Screening, 1999 \\
& Human Genetic Society of Australasia, Guidelines for the Practice of Genetic Counselling, 1999 \\
Austria & Part IV of The Gene Technology Act, 1995 \\
Belgium & None
\end{tabular}


Table Continued

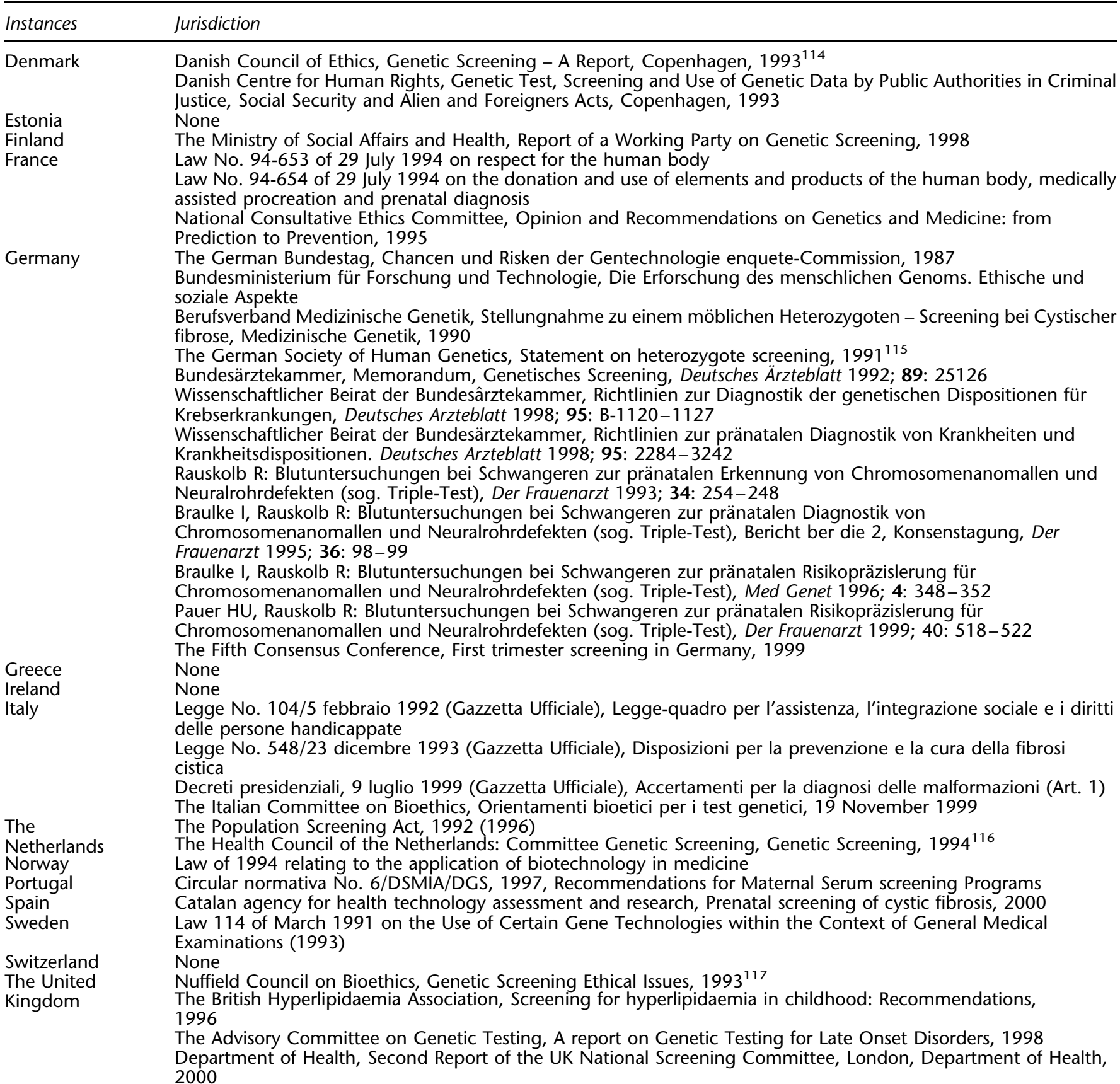

The ASHG Policy Statement for Maternal Serum alpha-fetoprotein Screening Programs and Quality Control for Laboratories Performing Maternal Serum and Amniotic Fluid alpha-fetoprotein Assays, 1987

Statement of The ASHG on Cystic Fibrosis Carrier Screening, 1990

Statement of The ASHG on Cystic Fibrosis Carrier Screening, 1992

The AMA, E-2.137 Ethical Issues in Carrier Screening of Genetic Disorders, 1994

The ACMG, Policy Statement: Fragile X Syndrome: Diagnostic and Carrier Testing, 1997

The ACMG Clinical Practice Committee, Principles of screening, 1997

The ACMG, Laboratory Standards and Guidelines for Population-based Cystic Fibrosis Carrier Screening, 2001

The AMA, Report 4 of the Council on Scientific Affairs (I-01) Newborn Screening: Challenges for the Coming Decade, 2001 
Table Continued

\begin{tabular}{ll}
\hline Instances & Jurisdiction \\
\hline Council of & Recommendation on Prenatal Genetic Screening, Prenatal Genetic Diagnosis and Associated Genetic Counselling, \\
Europe & 1990 \\
& Recommendation on genetic testing and screening for health-care purposes of the European Committee of \\
& Ministers, 1992 \\
Recommendation on Screening as a Tool of Preventive Medicine of the European Committee of Ministers, 1994 \\
WNESCO & International Bioethics Committee, Report of the Working Group on Genetic Screening and Testing, 1994 \\
WHO & WHO, Principles and Practice of Screening for Disease, Geneva: WHO, 1968 \\
& WHO, Guidelines on ethical issues in medical genetics and the provision of genetic services, 1995 \\
& WHO Technical Report Series, Control of Hereditary Diseases, Geneva: WHO, 1996 \\
& WHO, Proposed international guidelines on ethical issues in medical genetics and genetic services, 1997 \\
HUGO & None
\end{tabular}

International comparisons: legislation, policy statements, professional guidelines addressing indirectly the issue of genetic screening

\begin{tabular}{|c|c|}
\hline Instances & Jurisdiction \\
\hline Belgium & Article 5 of the 1992 law on Insurance Contracts \\
\hline \multirow[t]{4}{*}{ Denmark } & Danish Council of Ethics, Protection of Sensitive Personal Information - A Report, Copenhagen, 1992 \\
\hline & Danish Council of Ethics, Ethics and Mapping of the Human Genome, Copenhagen, $1993^{114}$ \\
\hline & $\begin{array}{l}\text { Danish National Board of Health, guidelines and recommendations for indications for prenatal diagnosis, } \\
1994\end{array}$ \\
\hline & Danish Council of Ethics, Priority-setting in the Health Services, 1997 \\
\hline Estonia & None \\
\hline Finland & $\begin{array}{l}\text { Primary Health Care Act and Decree, } 1971 \\
\text { Gene Technology Act } 1995\end{array}$ \\
\hline \multirow[t]{3}{*}{ France } & $\begin{array}{l}\text { National Advisory Committee on Bioethics and National College of Gynaecologists and Obstetricians Guidelines, } \\
1997\end{array}$ \\
\hline & $\begin{array}{l}\text { National Consultative Ethics Committee, Review of the Law of 1994: propositions regarding preimplantation } \\
\text { diagnosis and prenatal diagnosis, } 1998\end{array}$ \\
\hline & $\begin{array}{l}\text { Parliamentary Office for Evaluating Scientific and Technological Choices, Report on the application of the law of July } \\
29,1994 \text { concerning the donation and use of elements of the human body, medically assisted procreation and } \\
\text { prenatal diagnosis, } 1999\end{array}$ \\
\hline \multirow[t]{7}{*}{ Germany } & The Embryo Protection Law of 1990 \\
\hline & The German Society of Human Genetics, Statement on genetic diagnosis in childhood and adolescence, 1995 \\
\hline & The German Society of Human Genetics, Guidelines for molecular genetic diagnosis, 1996 \\
\hline & The German Society of Human Genetics, Guidelines for genetic counselling, 1996 \\
\hline & The German Society of Human Genetics, Position Paper, 1996 \\
\hline & The Professional Association of Medical Genetics, Principles of genetic counselling, 1996 \\
\hline & $\begin{array}{l}\text { Wissenschaftlicher Beirat der Bundesârztekammer, Richtlinien zur Durchfuehrung der assistierten Reproduktion, } \\
\text { Deutsches Arzteblatt 95, C-2230-2235, } 1998\end{array}$ \\
\hline Greece & None \\
\hline \multirow[t]{4}{*}{ Iceland } & Act no. $121 / 1989$ on Personal Privacy and Data Protection, Ministry of Health, 1989 \\
\hline & Act no. $97 / 1990$ on a Healthcare Services, Ministry of Health, 1990 \\
\hline & Act no. 74/1997 on the Rights of Patients, Ministry of Health, 1997 \\
\hline & Act no. $139 / 1998$ on a Health Sector Database, Ministry of Health, 1998 \\
\hline Ireland & None \\
\hline \multirow[t]{5}{*}{ Italy } & The Italian Committee on Bioethics, Prenatal Diagnosis, 17 July 1992 \\
\hline & The Italian Committee on Bioethics, Identity and Rights of the Embryo, 22 June 1996 \\
\hline & The Italian Committee on Bioethics, Human Genome Project, 18 March 1994 and 21 February 1997 \\
\hline & National Guidelines for Genetic Testing, 1998 \\
\hline & Law no. 675, 31 December 1996, D.P.R. no. 318, 28 July 1999, on Medical Information Privacy \\
\hline Norway & $\begin{array}{l}\text { Ministry of Health and Social Affaires, Biotechnology Related to Human Beings, Report No. } 25 \text { to the Storting, } \\
1992-3\end{array}$ \\
\hline \multirow[t]{3}{*}{ Portugal } & Act No $10 / 95$ related to the Protection of Personal Information \\
\hline & Despacho Ministerial No. 9108/97, Guidelines for Molecular Genetic Diagnosis \\
\hline & Despachos Ministerials No. 5411/97 e No. 10325/99, Principles and Practice for prenatal diagnosis \\
\hline \multirow[t]{4}{*}{ Spain } & The Spanish Constitution of 1978 \\
\hline & $\begin{array}{l}\text { Protocolos de Procedimientos Diagnosticos y Terapeuticos. Obstetricia. Medicina Materno Infantil (SEGO), Madrid } \\
1985\end{array}$ \\
\hline & General Health Law of 25 April 1986 \\
\hline & The Act 35/1988 of 22 November on Techniques of Assisted Reproduction \\
\hline
\end{tabular}


Table Continued

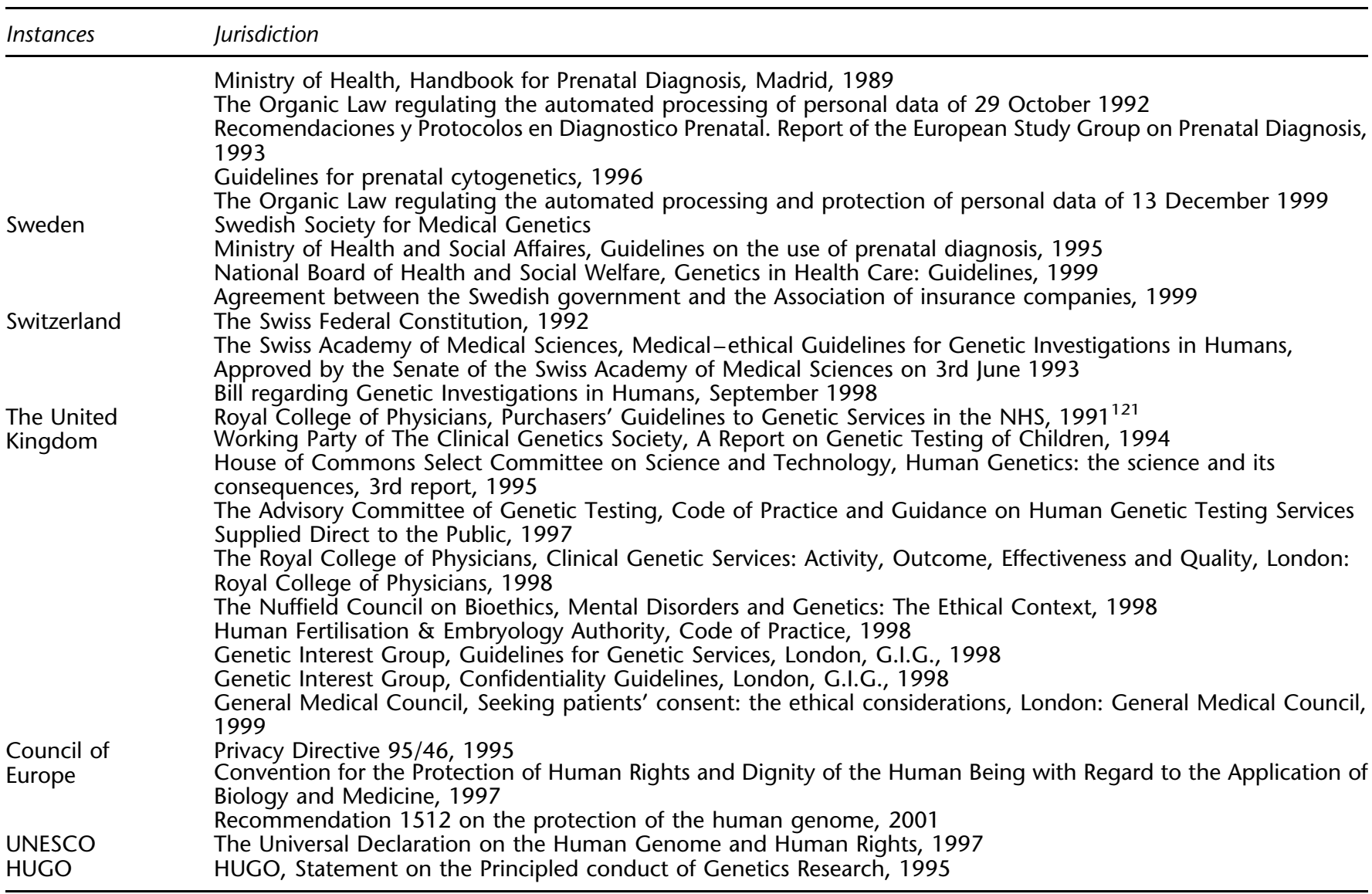

\section{Special issues}

From family testing to cascade screening to population screening Family testing, which is genetic testing from an index case to relatives, is a current practice in medicine. Individuals may wish to be tested if there is a family history of one specific disease, they show symptoms of a genetic disorder, or they are concerned about passing on a genetic problem to their children. For those whose test results are positive the decision about whether to suggest tests to relatives is left to their discretion. Genetic testing is increasingly being offered to family members at all stages of the life cycle. These tests can either be screening tests or diagnostic tests.

There are two main approaches in genetic screening: screening along family lines starting from an index case (cascade screening, eg screening for familial hypercholesterolemia) and screening without taking family history into account, e.g. neonatal screening for PKU). Cascade screening involves the diagnosis of an affected individual followed by the systematic identification and testing of relatives. The impact of cascade screening is relatively low. $^{122}$ Even if the disease is known in the family, information on the genetic risk may only be disseminated to a minority of those relatives at risk or relatives may refuse to be tested and using individuals within families to initiate the contacts with distant relatives, which is necessary when cascading goes further than about the first-cousin level, is an activity that is likely to make genetic counsellors unpopular in the community. ${ }^{123}$ But, even with these factors, it has been argued that cascade screening remains more efficient than general population screening and has the advantage that the detected carriers have, in general, better knowledge of the disease because they may know an index case. ${ }^{55}$

Population-based screening is an alternative to cascade screening. Population-based screening is more effective than cascade screening in giving the highest number of carrier couples an informed choice about reproduction. The options are accepting the risk and just go on, refraining from biological children, with or without adoption, AID or egg cell donation, prenatal diagnosis, or preimplantation diagnosis. The experience with autosomal 
recessive disorders suggests that those who find themselves at risk of bearing a child with a recessive disorder is to ask for prenatal diagnosis and a monitored pregnancy. ${ }^{124}$

The method in which screening is offered (personal invitations, mails, leaflets) is a major determinant of acceptance rates. For example, it has been reported that all the following are needed in connection with screening for the hemoglobin disorders: general information for the public and for pregnant women, posters and leaflets to encourage carrier testing, diagnosis-specific information for the carriers identified, information for couples where both partners have been tested, complete information for at-risk couples, information to patients and families about each disorder and its treatment, and guidelines for doctors on treatment and prevention as well as for service planners. ${ }^{125}$ The likelihood that carrier screening would be closely tied to prenatal diagnosis has influenced the discussion of when to perform screening. One school of thought argues that the most effective time is during pregnancy. ${ }^{60} \mathrm{~A}$ different view suggests that screening during pregnancy places an undesirably heavy burden of decision-making on a susceptible and captive group, and that individuals must be allowed to make up their minds about the implications of carrier status before a pregnancy. ${ }^{106}$

The Informed Consent Issue In opposition to ordinary clinical practice in which investigations are carried out on individuals with symptoms who seek medical help, in a genetic screening programme, healthy individuals are approached for investigation and a percentage are identified as being at risk of a disorder to justify an intervention. Deciding not to take part may also have consequences. In all cases, individuals who are offered genetic screening are faced with having to make a choice. It is therefore essential that approached individuals consent to join with knowledge and understanding of the screening test, together with the limitations of the test, so that they can decide whether they wish to be screened.

With very few exceptions, to comply with the law and the medical deontology, the right of an individual to take a free and informed decision on the performance of a test which may reveal in his genetic make-up the presence of a mutant gene that, whatever the result, could have an effect on his life must be respected. For that to be done, three conditions must be fulfilled: (1) sufficient understanding of the implications of a decision that implies information on the nature of the test, the significance of the results, and existing prevention and therapy; (2) freedom of choice and absence of any form of constraint; and (3) legal capacity to give a free and informed consent. ${ }^{126}$

However, the extensive and intricate nature of genetic information, and the unfamiliarity of most people with this area, brings into doubt whether obtained consent is free and informed. Various studies have examined indivi- duals' experiences of screening and the activities of health professionals who provide a genetic screening programme. It appears that obtaining truly informed consent for a complex test, such as MSAFP screening, is not a simple process. Participants met a few, but not all, of the criteria for informed consent. Women understood that the test was voluntary, but their comprehension of the meaning and implication of a positive test results was deficient. Despite this, they signed the informed consent document. ${ }^{127}$ Other studies have shown that individuals have difficulties to understand the result of a CF carrier test and the risk of having a CF child. In one case, the difficulties were complicated by the limited sensitivity of the DNA test. ${ }^{128}$ In the other case, it was the method of testing (two-step method or couple method) that affected the understanding of the implication of the test result. ${ }^{129}$

Even when properly understood, informed consent presents an array of ongoing problems and unanswered questions. These include the question of how much information must be given to patients, and how much is too much; and how to ensure the full voluntariness of subjects' consent. ${ }^{130}$ Sometimes more information is associated with increased understanding of the concept and sometimes divulging less information seems to be associated with less anxiety. However, it would be irrespective of consent method. There is some evidence to suggest that there is an optimal amount of information that enhances patient understanding and which might, in turn, reduce anxiety and possible harm. ${ }^{131}$ The British General Medical Council's guidance on seeking patients' consent (1999) makes it clear that physicians must make sure that patients are provided with all the information they want or ought to have to make a properly informed decision.

The family-connection The genetic nature of a disorder often results in risk implications to family members of the person screened, even though they may not be or perhaps wish to be included in the screening programme. They may even have no prior personal experience of the disorder that may be detected. This situation has psychological consequences for the individuals and their families. Screening can give confidence and reassurance but also anxiety. Adequate counselling and the provision of information that is both balanced and accurate can play a crucial role, but the amount of counselling that can be offered to a screened population is often minimal because of the resource implications.

According to The Health Council of the Netherlands, ${ }^{116}$ before implementing a genetic screening programme consideration must be given to whether the principle of 'do not harm' justifies confronting people with choices that are often very difficult to make. Unless effective treatment is available for improving the quality of life of a person with a disorder, screening constrains individuals to make decisions about having children, lifestyle and how to 
live the rest of one's life. Since having certain genetic traits may not affect one's health, nor lead to the development of a disease, it is important to consider the benefits and risks of knowing whether the trait is present or not. Subsequent to being identified as a carrier, some have reported experiences with stigmatization and subsequent problems with low self-esteem. Developments of new tests may exacerbate these issues and needs further exploration.

In other respects, the implications of carrier screening on family and social relationships require that the interests of the individuals be balanced against the interests of other individuals and of society as a whole. Tension can develop between the right of an individual to confidentiality and the right of other individuals to be informed of potential harms. In 1975, the American Committee for the Study of Inborn Errors of Metabolism stated that the results of screening should be disclosed to others without consent only when necessary for the patient's medical care or to protect others from risk created by the patient's condition. it has been proposed that when disclosure is considered necessary, it should be limited to the minimum necessary information. These guidelines would apply not only to individuals but also to entities such as insurers and employers that might benefit from this. ${ }^{132}$

Multidisorders screening Advances in DNA-based diagnostic procedures have led to a rapid increase in the number of genetic disorders and mutations of one disorder for which screening is possible. A panel of rapid and economical screening tests becomes increasingly available. These tests can be used to find information about disease, carrier or susceptibility status for multiple disorders or mutations on a single pass. ${ }^{133}$ It will then become increasingly difficult, if not impossible, to inform those offered screening about all the genetic information that can be obtained and the implications of that information. ${ }^{133}$ In a setting of genetic screening, what is at stake is the right to decide whether or not to have a genetic test, with emphasis on the right to refuse. To respect selfdetermination and rational decision-making, it has been proposed to develop a 'generic consent for genetic screening' that would emphasize broader concepts and commondenominator issues in genetic screening. ${ }^{134}$ The aim is to provide sufficient information to permit patients to make informed decisions about genetic screening, yet avoid the information overload that could lead to misinformed consent.

Commercialization Medical interest, patients' demand, or awareness of the available testing opportunities are factors that may lead to an increase in genetic tests market. However, given the amount of financial investment in the area, the need to maintain the confidence of potential investors, and the media hype that often surrounds a new genetic discovery, many fear that a myriad of novel genetic services will be offered to the public before the legal and social ramifications have been fully explored. ${ }^{135}$ Concerns are expressed about the possibility of offering a test even if it is not medically indicated as well as the monitoring of technical quality, the availability of counselling and follow-up facilities, the standards of confidentiality or the costs and benefits of genetic testing services. ${ }^{136}$ Studies have shown that the counselling and consent processes that ought to accompany commercial services have been found to be insufficient. ${ }^{137,138}$ Inversely, other studies have shown that quality control of screening tests as well as quality information of direct marketing of these tests to the public have been proved for CF carrier screening in UK. ${ }^{139}$ But the cost of the test, the difficulty of finding time for counselling and lack of consensus about the need for screening are cited as reasons for not implementing screening programmes. For some people, such arguments make private screening inevitable as they assume that the public will demand such tests.

Marketing and advertising strategies used by the biotech/ pharmaceutical industry are also criticized as an inappropriate means of conveying medical information. ${ }^{140,141}$ Although research seems to indicate that patients support this type of advertising, health-care providers believe that it undermines the physician/patient relationship by encouraging unreasonable patient demands for services. ${ }^{142}$ Others consider that 'commercial push may be a good way of assessing population need' because individuals get to weigh the benefits and hazards of a screening test before requesting it. ${ }^{16}$ However that may be, if high-risk cases may be diagnosed, would it be as part of the patients' rights, it remains an unanswered question, whether or not everybody has the right to know their genetic outfit for no direct health reasons, even if paid privately. Nevertheless, there are only a few diagnostic services that are sold commercially. For example, in Europe, a large quality assessment of CFTR gene mutation testing methods shows that only a minority of the participating laboratories makes use of the commercially available mutation detection kits. ${ }^{143}$

In UK, The Advisory Committee on Genetic Testing ${ }^{144}$ has recommended that companies wishing to sell genetic tests through the mail be restricted to carrier testing. This approach has been found too permissive. ${ }^{145}$ In the Netherlands, the Health Council ${ }^{116}$ has suggested to restrict genetic tests to what is medically appropriate. Commercial tests and services offered through health-care system seem to offer the best possibilities for control and regulation. ${ }^{137,146}$ Advantages are better possibilities for counselling and support. Follow-up in the form of preventive measures might be easier to arrange, and in cases of prenatal tests selective abortion for conditions generally felt to be not serious could be more easily discussed. The possibility of misuse can perhaps not be avoided, but may be acceptable in view of the advantages of preconception commercial genetic carrier screening. ${ }^{146}$ 
A case can be made to provide certain genetic tests directly to the public. ${ }^{146}$ These should meet certain conditions. An overseeing body in which all interested parties are represented could take on the task of deciding which tests ought to be offered through health care and which offered directly. This body could also assess their quality, the information provided and test interpretations and discuss the need for reimbursement. Reimbursement could be a means to enforce quality control or to meet other criteria.

The players on the scene 'A genetic screening programme will only be effective if it is accepted by the target population and the medical profession' said the French National Ethical Consultative Committee in 1995. ${ }^{147,148}$ The way in which the risk of onset of a severe illness is viewed varies in different groups and individuals. Certain diseases, although frequent, remain obscure for various reasons: no characteristic phenotypic expression (CF), secrecy observed by families (frequently occurring in cases of mental retardation, for instance fragile $\mathrm{X}$ syndrome), inequalities of access to genetic services particularly for minority ethnic groups or no professional consensus on the implementation of a screening program. Participation by the medical profession, in particular by primary-care physicians who are involved in interpreting results to patients and families following the encounter with the geneticist, is also essential for a screening programme to be successful. The way in which screening is offered can also influence the way in which society views people with identifiable handicaps: balanced information will ensure that they are not seen as the result of missed opportunities for prevention. Anyhow, a high rate of participation should not be a goal as such.

The venue through which screening is offered may have substantial implications on the provider-patient relationship as well as on the utilization of genetic services and other medical services (laboratories, primary care clinics). Screening creates obligations to follow-up with a more specific diagnostic test, as well as a possible responsibility to recontact or update individuals as improved screening tests are developed. Information and counselling are a sine qua non. The costs and social implications of these new obligations should be factored into the decision to initiate a genetic screening programme. ${ }^{6,99}$ Time constraints, both lack and plethora of knowledge, low tolerance for diagnostic ambiguity can impede the physicians to meet an adequate standard of care, would it be to obtain informed consent, to provide genetic counselling or to follow patients on a long-term basis. It has been argued that the increasing use of genetic tests will render the provision of pretest counselling impracticable. ${ }^{111}$ It is likely that counselling will be kept for positives only. Already commercial companies offer testing by post without any pretest counselling, for CF carrier status and the triple test.
In addition to medical specialists, appropriate service development also requires the formation of multidisciplinary groups, development of an appropriate infrastructure including trained genetic counsellors, and collaboration with patient support associations. ${ }^{125,105,148}$

In other respects, the high degree of technicality and diversity of genetic tests implies specialized laboratories as this is an essential condition for sustained technical quality of results and of their interpretation. Procedure for habilitation and quality control must be established. A quality control trial conducted by the European Concerted Action on Cystic Fibrosis has shown that many laboratories (35\%) have a percentage of errors unacceptable in a routine testing setting. In order to improve genotyping, it has been recommended to develop a consensus testing strategy for routine diagnostic laboratories and centralized mutation analysis facilities for rare or country-specific mutations in a limited number of expert centres, in combination with regular training sessions and quality assessments. ${ }^{143}$ For tests to be performed on a vast number of people, feasibility and reliability pilot studies must be undertaken before starting. ${ }^{99,149}$ The results will need to be examined with discernment since a pilot study is carried out in privileged circumstances, which do not necessarily tally with those of a routine testing procedure (quality and motivation of participants, including, frequently, tested individuals themselves) (National Ethical Consultative Committee 1995).

In spite of all these considerations, the stress on individual counselling raises the question of whether genetic screening should benefit the individual or society and whether these are in opposition. Currently, decisions are made by the individual or couple, although what decisions can be made may be limited by resources and legal restrictions. It was acknowledged that in the area of public health genetic screening programmes will be seen as a way of cutting costs as well as individual suffering. ${ }^{111}$ In Denmark, it has been estimated that the future savings on health-care expenditures resulting from 1 year of neonatal screening for phenylketonuria and congenital hypothyroidism are 28 times higher than the cost of screening. ${ }^{150}$ The authors consider that it is desirable to expand the existing screening programme to include a range of rare inherited metabolic diseases, which collectively are frequent. This seems realistic with the advent of tandem mass spectrometry, which allows cost-effective simultaneous screening for a group of inborn errors of metabolism. In Finland, screening for fragile $\mathrm{X}$ mutations in low-risk pregnancies has shown that if avoiding the treatment costs incurred by an affected individual is seen to be a benefit for society as a whole, then screening seems economically justifiable. ${ }^{60}$ However, in the cases where treatment options are limited, it is recommended to have safeguards that protect individuals from pressures to adopt options, such as avoiding conception or terminating affected fetuses, just because they 
would be cheaper than the clinical management of an individual with the disease. ${ }^{136}$

Evaluating genetic screening programmes Programme evaluation is supposed to provide objective information on the effects of a service in order to inform those in charge of establishing policies and allocating resources. ${ }^{6}$ Identifying worthwhile screening programmes, developing the correct strategies, and implementing them effectively is no easy task. Monitoring, evaluation and quality control are important components for all new screening programmes. Even when the same test is used for screening and for diagnostic testing, its predictive value (proportion of persons testing positive who have the condition or testing negative who do not have the condition) will differ. Changes to sensitivity (ability of the test to detect all those who have, or who will develop, the disease), specificity (ability to classify correctly those persons who do not have or will not develop, the disease), and predictive value of a genetic test occur when moving from a population with a high prevalence to one of low. This could reflect either a lower prevalence of the disorder and a consequent drop in the positive predictive value of the test or a weaker correlation between genotype and overt disease in the general population due to ascertainment bias in the original population. ${ }^{6}$ What constitutes a reasonable sensitivity, specificity, or positive predictive value can vary from one disorder to another and is a function of both the performance characteristics of the tests and the value assigned to a false or missed identification as compared to the benefit of identifying cases. ${ }^{136}$ Issues of test reliability (the ability of a test to correctly assign people to a group on repeated measures and evaluates the variation due to the testing method) and validity (the ability to identify people correctly as either having, or not having, the genetic trait) need also be addressed. ${ }^{99,6}$

Combinations of screening techniques have been proposed in order to detect a reasonable proportion of individuals at risk for a disorder. For Down's syndrome, both first-trimester screening and second-trimester screening are effective means of selecting women for CVS or amniocentesis, but there is uncertainty about which screening method should be recommended at the population level. If several screening tests are offered sequentially during the pregnancy, the risk estimated should be based on all test results whatever their timing. ${ }^{151,152}$ For CF, several CFTR mutation detection methods have also been evaluated. ${ }^{143,153}$ The proficiency (the correct interpretation and timely, unambiguous, reporting of results) must apply within the same laboratory as well as across laboratories. ${ }^{154}$ Consequently, reliability, validity, and proficiency measures should be regulated and assessed on a regular and continuing basis. ${ }^{6}$

Another issue that need to be considered when extending tests from the research setting to widespread screening is that the test may not be easily adaptable for widespread use for economic reasons. ${ }^{6}$ The cost of screening is another important issue in programme evaluation. However, it is often limited to the financial aspect, compared with that of treating an individual with the disease or estimated per disease-associated genotype detected. The cost-benefit analysis are based on technical considerations that measure the impact of programmes and how well they attain their stated objectives. ${ }^{6}$ Although criteria for quantifying benefit may be appropriate from a scientific perspective, the perception of those being tested might differ. A much more critical approach to screening has been adopted and efforts have been made to ensure that new programmes of proven benefit and which are acceptable to the public, are effectively and equitably implemented in the community. $^{155}$

Surveys suggest that practice of screening is not uniform and that there is a lack of systematic evaluation. ${ }^{156-158}$ Discussion of screening has focused largely on test characteristics and performance against a gold standard with less attention being given to issues of policy formation, priority setting, implementation and quality assurance of the effectiveness, efficiency and safety of the test procedure. But without these elements, it has been reported that quality and test performance deteriorate, as recruitment and follow-up are incomplete. $^{156}$

In UK, a framework for the evaluation and implementation of national screening programmes has been set out. The aim is to ensure that screening programmes are not introduced into the National Health Services unless there is robust evidence that benefit outweighs harm. ${ }^{159}$ For that, ideally policy decisions about new screening initiatives should be informed by evidence from randomized controlled trials but for most of the conditions for which a screening programme proposed, large trials would be needed. ${ }^{160}$ In Scotland, suggestions have been made to improve quality and relevance of screening: (1) national guidelines should be formulated to promote the implementation of the same core screening activities in all Boards; (2) audit and quality control programmes should be universal and systematically applied; (3) the demarcations of professional and managerial responsibilities and lines of accountability should be clarified; (4) any proposed new screening programmes should be assessed in the light of the classic World Health Organization principles before their introduction. ${ }^{157}$ In USA, the Task Force on Genetic Testing has identified several problems affecting safety and effectiveness of new genetic tests, as defined: validity and utility of genetic tests, laboratory quality, and appropriate use by health-care providers and consumers. On the basis of these findings, the Task Force recommended 'policies that will reduce the likelihood of damaging effects so the benefits of testing can be fully realized undiluted by harm'. ${ }^{136}$ 


\section{Discussion}

The workshop organized by the ESHG (1999) highlighted the different point of views expressed by health-care providers and patients organizations on the risks and benefits that come with new genetic tests. It showed how various uptake rates are influenced by provider behavior, by how the test is offered and to whom the test is offered. It also demonstrated the scrutiny that went internationally into the efforts to safeguard new genetic testing.

Arguments for and against starting screening programs have been put forward. In accordance with the Dutch Health Council definition, a genetic screening programme consists in 'any kind of test performed for the systematic early detection or exclusion of a hereditary disease, the predisposition to such a disease, or to determine whether a person carries a predisposition which may produce a hereditary disease in offspring'. It has been questioned whether genetic screening differs from other types of screening and testing in terms of ethical issues. The general impression on the future of genetic screening is that one wants to 'proceed with caution', with more active impetus from the side of patients organizations and more reluctance from the policy-makers. The latter try to obviate the potential problems about the abortion and eugenics issues which might be perceived as a greater problem than it is in reality. However, it seems important to maintain a balance between a 'professional duty of care' and 'personal autonomy'.

\section{Genetic screening programmes before birth}

Genetic screening includes a wide variety of procedures. Technical limitations of these procedures as well as ethical implications have been discussed. Before birth, screening on fetal cells in maternal blood is still in its early stages. Given the rarity of the most successful fetal cells in maternal blood, sophisticated techniques are required to obtain an adequate sample of these cells for analysis. Screening on fetal cells in maternal blood will be an alternative to CVS or amniocentesis but will not replace them: women with a positive result will ask for an invasive prenatal diagnostic test before deciding for a termination of pregnancy.

Maternal serum screening participation is high. In France, although $97 \%$ of women sign a consent form before screening, only $80 \%$ appear to have received an appropriate information. Although the problem of proper counselling expectant mothers before and after the test has been well documented, it is reminded that to ensure free informed decision making whether to have a triple test or not, it is of the utmost importance to discuss the 'sequence of decisions' before the offer of the triple test. After a positive triple test result, the importance of genetic counselling allows a full discussion of all options in a situation of increased genetic risk and a free informed choice by parents.
Ultrasound screening for nuchal-translucency thickness can detect about $80 \%$ of trisomies. Unlike invasive procedures, it is socially acceptable almost everywhere. Effectiveness should increase by enhancing education and training and the systematic referral for fetal anomalies screening to accredited laboratories. Women identified by ultrasound as at risk are offered invasive procedures. Even if the advance of the capacities of ultrasound screening raises psychological issues for these pregnant women because they have to make an active and quick decision about whether to continue with their pregnancy, it is reported that ultrasound screening remains the preferred prenatal screening strategy for most women. ${ }^{161}$

Screening on fetal cells obtained by CVS has a higher rate of false-positive results $(1-1.5 \%)$ as compared with amniocentesis $(0.5 \%)$. Each procedure has less than 1 in 10000 false-negative results. The sampling of fetal cells obtained by amniocentesis or CVS in order to make lists of disorders for which PND should be available or offered is rejected.

Finally, discussing preimplantation genetic diagnosis, it has been reported that in Belgium, $1 / 3$ of clients requested it because of fertility problems, $1 / 3$ because of repeated miscarriages or terminations of pregnancy after PND, and $1 / 3$ on religious or ethical grounds. PGS will always have false-negative results, because $1 / 3$ to $1 / 5$ of embryos are mosaics. The experience with preimplantation genetic diagnosis is as yet small and much remains to be done to clarify success rates, diagnostic accuracy risks and longterm effects on the offspring.

\section{Genetic screening programmes after birth}

Discussions on genetic screening after birth have focused on disorders for which screening programs are debated. The inclusion of screening for conditions such as CF and DMD are currently being discussed throughout the countries. Although the original intent of neonatal screening is to identify genetic conditions in order to initiate early treatment and to prevent complications, the identification of new genes and technologies is extending the limits of what can be identified at the time of birth, oftentimes in the absence of treatment. This trend raises novel issues such as the systematic neonatal screening by using a test that can be performed on the blood spots routinely collected in screening for phenylketonuria and hypothyroidism, the methods and number of mutations to be tested, quality control, as well as the methods for presenting information.

In the UK, neonatal screening has been proposed for CF, on the basis of early intervention in both nutrition and infection. It has been reported that by 2 months and half, $40 \%$ of infants have lower bronchial infections. At the time of diagnosis, infants with CF are two standard deviations below the mean in weight, although they catch up around the age of 2 years. However, there is no evidence of any long-term effect of this nutritional compromise. Now $20 \%$ 
of newborns are screened and the programme is costeffective in terms of reduced mortality, even though on average screened infants are only diagnosed about 1 month earlier than unscreened infants.

Neonatal screening for DMD has been also recommended. In the United Kingdom, the Welsh research evaluation of newborn screening for DMD indicates that the great majority of identified families are in favor of screening and there has been no evidence of any long-term disruption in either the mother/baby relationship or family stability. Of 129000 families who received information, 92\% requested to have their child tested. Their reasons were right to know, planning for the future, and time to prepare emotionally. The parents of only two of the 22 children with DMD had post-decision regret. Concerning subsequent pregnancies, $74 \%$ of families had a prenatal diagnosis. There was no evidence of parental rejection of their living children identified as having DMD. In other respect, families changed their reproductive patterning after the neonatal diagnosis; there was a delay in family building reflected in the birth interval between index and second birth. These data confirm what Parsons et al ${ }^{162}$ observed in 1996, namely genetic screening programmes for DMD should only be introduced if there is a rigorous protocol in place for handling positive cases and provision of ongoing support for identified families.

Genetic screening for fragile-X appears premature. Its prevalence is unknown, estimated at 1 in 2000 to 1 in 6000. There is an overlap between the 'normal' number of CGG repeats and the premutation number of repeats, further complicated by the possibly stabilising effect of varying numbers of AGG repeats within the CGG repeats. Furthermore, the number of repeats that may be unstable in families with fragile- $X$ may be stable in the general population, suggesting that something else than the number of repeats is affecting these particular families. Fragile-X is underdiagnosed, resulting in lack of prevention of new cases. Ideally, the diagnosis should be made when the parents first notice 'something wrong', usually at about 1 year. This would relieve the parents of uncertainty and guilt. Finally, it has been suggested to screen pregnant women and women seeking preconceptional counselling, but only if questions about the overlap between normal and premutation can be answered.

Genetic screening for familial hypercholesterolemia seems also arguable. This type of screening is complicated by divergences between genotype and phenotype. Some individuals with familial hypercholesterolemia mutations do not have high cholesterol. Further, individuals with familial hypercholesterolemia mutations and high cholesterol develop heart disease at differing ages and with differing severity. Biochemical screening for cholesterol may be preferable to genetic screening. Similar genotypephenotype divergences have been observed for hemochromatosis screening. The place of the DNA test in the diagnosis and management of the disorder is not yet clear.

Are antenatal clinics the right place for carrier screening? Antenatal screening provides an effective way of identifying carriers and incorporating prenatal testing in this process. Carrier screening at antenatal clinics is easy to organize: the risk of being a carrier is of current interest and the partner already exists. On the other hand, couples have less options than before the pregnancy, time for decisionmaking is limited, and because of the pregnancy, carrier screening may cause extra anxiety. Couples may also be too stressed to make truly informed decisions. In other respects, the partner may not be available. In Finland, two pilot programmes have been set up for aspartylglycosaminuria screening. These programmes have been well received with a high rate of participation. The reasons given were (1) the health of the baby (93\%) and (2) the participation in all tests offered (86\%).

Of all the types of genetic screening, preconceptional carrier screening is the preferred way to go. However, the organization of adequate facilities to meet the demand for screening is essential. In the UK, it has been reported that screening for hemoglobinopathies in primary care could be enhanced; especially a multidisciplinary approach and a diagnosis laboratory responsive to the needs of local practitioners are important and facilitators like nurses can be particularly successful in persuading single-handed practitioners practising in areas with a high prevalence of ethnic groups to increase their testing for carriers. Simultaneously, additional approaches are necessary: for example, a strategy within the maternity services for taking parental blood in early pregnancy, especially in areas with a high proportion of ethnic groups, since preconceptional carrier screening is unlikely to replace antenatal screening. It is also recommended to pay more attention to minority groups. Results of a survey conducted by the Genetic Interest Group show that only five of 27 British genetics clinics recorded patients' ethnicity. Practitioners were left to determine patients' ethnic origins.

\section{The decision-making process}

It has been reported that attention should always be paid to the possible psychological consequences for people who have decided not to take part in a screening programme and who are confronted with the birth of a child suffering from a disorder that screening would have detected. It has been observed that if they did not take this possibility sufficiently into account when they decided not to participate in screening, they may experience feelings of guilt and remorse. Proper information appears to be the only way to prevent this happening. To do so, an ongoing educational effort for groups of professionals and for the general population is essential to safeguard 'free informed decision making' in a context of genetic screening and to stimulate better coping in families confronted with genetic disease. 
For that, underdisclosure and overloaded information should be avoided. It has been argued that informed consent is not an event, but a process of communication between a health provider and a patient at all the stages of the screening process.

\section{Conclusion}

Are population genetic screening programmes needed? Genetic testing is now a well-established part of medical care, which may benefit a number of different groups of individuals. Given the rarity of serious genetic conditions, the development of genetic screening programs, even in the light of new genetic knowledge, will not lead to the testing of all individuals. Instead, the offer of a test to a large subgroup of them, with the aim of identifying those at higher risk so that more specific tests may be offered could be considered. The number of conditions for which this might be considered would be small. For the population as a whole, CF is the obvious example and for ethnic groups, thalassemia is another example. Where screening programs of this type exist and are well organized, the participation rate is generally high, indicating that they satisfy a genuine need.

Simultaneously, experiences with population screening (eg hemoglobin disorders) have demonstrated the necessity to build up an interconnected comprehensive infrastructure of services, to educate physicians and the population to be screened not only about the nature of the disorder itself but also about the limits of the tests that are available to avoid unnecessary harm. It is agreed upon that one of the main problems is how appropriately controllable is the evolution of standards of practice by the medical profession as new powerful diagnostic tests rapidly become available by the new genetics. Protocols for screening programmes should be developed on basis of research evidence and caution should be taken for conditions for which there is no treatment.

It is agreed upon that if genetic screening programmes would be offered on a population basis a number of complex problems has to be solved, that is, who should be offered testing and in what setting? How should the lack of public understanding of genetics be dealt with? How should the training of health-care providers be improved ? How can individual autonomy be safeguarded? What kind of procedures should be taken to ensure the quality of genetic counselling?

Consensus has been reached that informed choice is the basis of every genetic screening programme. Because the majority of the population is as yet relatively uninformed, counselling is necessary to safeguard individual autonomy and choices. Health professionals' awareness and knowledge of genetics have to be improved. Collaboration with patients organizations is also needed to ensure that information surrounding the offer of a screening test reflects the perceived impact of the condition from the perspective of those affected, and provides information that those living with the condition would have found helpful had it been available prior to the offer of the test.

\section{References}

1 Committee for the Study of Inborn Errors of Metabolism: Genetic screening: programs, principles and research. Washington, DC: National Academy of Sciences; 1975.

2 The Nuffield Trust Genetics Scenario Project: Genetics and Health. Policy issues for genetic science and their implications for health and health services. London: The Stationery Office; 2000.

3 WHO Wilson JMG, Jungner G: Principles and practice of screening for disease. Geneva: WHO; 1968.

4 Goel V: Appraising organised screening programmes for testing for genetic susceptibility to cancer. BMJ 2001; 322: 1174-1178.

5 Hoedemaekers R, ten Have H, Chadwick R: Genetic screening: a comparative analysis of three recent reports. J Med Ethics 1997; 23: $135-141$.

6 Stranc L, Evans J: Issues relating to the implementation of genetic screening programs. in Knoppers BM (ed): Socio-ethical issues in human genetics. Montreal: Les Editions Yvon Blais Inc.,; 1998, pp 49-105.

7 Alderson P, Aro AR, Dragonas T et al: Prenatal screening and genetics. Eur J Public Health 2001; 11: 231-233.

8 Austoker J: Gaining informed consent for screening. BMJ 1999; 319: $722-723$.

9 General Medical Council: Seeking patients' consent: the ethical considerations. London: General Medical Council; 1999.

10 Delvaux I, van Tongerloo A, Messiaen L et al: Carrier screening for cystic in a prenatal setting. Genet Test 2001; 5: 117-125.

11 Henneman L, Bramsen I, van der Ploeg HM et al: Participation in preconceptional carrier couple screening: characteristics, attitudes, and knowledge of both partners. J Med Genet 2001; 38: $695-703$.

12 Wald NJ, Kennard A, Hackshaw A, McGuire A: Antenatal screening for Down's syndrome. J Med Screen 1997; 4: 181-246.

13 Al Mufti R, Hambley H, Farzaneh F, Nicolaides KH: Investigation of maternal blood enriched for fetal cells: role in screening and diagnosis of fetal trisomies. Am J Med Genet 1999; 85: 66-75.

14 Miny P, Tercanli S, Holzgreve W: Developments in laboratory techniques for prenatal diagnosis. Curr Opin Obstet Gynecol 2002; 14: 161-168.

15 Brock DJ, Sutcliffe RG: Alpha-fetoprotein in the antenatal diagnosis of anencephaly and spina bifida. Lancet 1972; 2: 197-199.

16 Cuckle HS, van Lith JM: Appropriate biochemical parameters in first-trimester screening for Down syndrome. Prenat Diagn 1999; 19: $505-512$.

17 Cole LA, Shahabi S, Oz UA et al: Urinary screening tests for fetal Down syndrome: II Hyperglycosylated hCG. Prenat Diagn 1999; 19: 351-359.

18 Marteau T: Towards informed decisions about prenatal testing: a review. Prenat Diagn 1995; 15: 12515-12526.

19 Nippert I, Horst J, Schmidtke J: Genetic services in Germany. Eur J Hum Genet 1997; 5 (Suppl 2): 81-88.

20 Bassett M, Dunn C, Battese K, Peek M: Acceptance of neonatal genetic screening for hereditary hemochromatosis by informed parents. Genet Test 2001; 5: 317-320.

21 Snijders RJ, Johnson S, Sebire NJ, Noble PL, Nicolaides KH: Firsttrimester ultrasound screening for chromosomal defects. Ultrasound Obstet Gynecol 1996; 7: 216-226.

22 Wald N, Kennard A: Routine ultrasound scanning for congenital abnormalities. Ann NY Acad Sci 1998; 847: 173-180. 
23 Levi S: Routine ultrasound screening of congenital anomalies. An overview of the European experience. Ann NY Acad Sci 1998; 847: 86-98.

24 Snijders RJ, Noble P, Sebire N, Souka A, Nicolaides KH: UK multicentre project on assessment of risk of trisomy 21 by maternal age and fetal nuchal-translucency thickness at 10-14 weeks of gestation. Fetal Medicine Foundation First Trimester Screening Group. Lancet 1998; 352: 343-346.

25 Pajkrt E, van Lith JM, Mol BW, Bleker OP, Bilardo CM: Screening for Down's syndrome by fetal nuchal translucency measurement in a general obstetric population. Ultrasound Obstet Gynecol 1998; 12: 163-169.

26 Schwarzler P, Carvalho JS, Senat MV, Masroor T, Campbell S, Ville Y: Screening for fetal aneuploidies and fetal cardiac abnormalities by nuchal translucency thickness measurement at 10-14 weeks of gestation as part of routine antenatal care in an unselected population. Br J Obstet Gynaecol 1999; 106: 10291034.

27 Devine PC, Malone FD: First trimester screening for structural fetal abnormalities: nuchal translucency sonography. Semin Perinatol 1999; 23: 382-392.

28 Snijders RJ, Thom EA, Zachary JM et al: First-trimester trisomy screening: nuchal translucency measurement training and quality assurance to correct and unify technique. Ultrasound Obstet Gynecol 2002; 19: 353-359.

29 McFadyen A, Gledhill J, Whitlow B, Economides D: First trimester ultrasound screening carries ethical and psychological implications. BMJ 1998; 317: 694-695.

30 Brambati B: Prenatal diagnosis of genetic diseases. Eur J Obstet Gynecol Reprod Biol 2000; 90: 165-169.

31 Handyside AH, Kontogianni EH, Hardy K, Winston RM: Pregnancies from biopsied human preimplantation embryos sexed by Y-specific DNA amplification. Nature 1990; 344: $768-770$.

32 Geraedts J, Handyside A, Harper J et al: European Society of Human Reproduction and Embryology Preimplantation Genetic Diagnosis Consortium Steering Committee, ESHRE preimplantation genetic diagnosis (PGD) consortium: data collection II (May 2000). Hum Reprod 2000; 15: 2673-2683.

33 Harper JC, Wells D: Recent advances and future developments in PGD. Prenat Diagn 1999; 19: 1193-1199.

34 Pembrey ME: In the light of preimplantation genetic diagnosis: some ethical issues in medical genetics revisited. Eur J Hum Genet 1998; 6: 4-11.

35 The Ethics Committee of the American Society of Reproductive Medicine: Sex selection and preimplantation genetic diagnosis. Fertil Steril 1999; 72: 595-598.

36 Levi HL, Albers S: Genetic screening of newborns. Annu Rev Genomics Hum Genet 2000; 1: 139-177.

37 Motulsky A: Screening for Genetic Diseases. N Engl J Med 1997; 336: $1314-1316$.

38 Therrell Jr BL: US newnorn screening policy dilemmas for the twenty-first century. Mol Genet Metab 2001; 74: 64-74.

39 Cao A, Galanello R, Rosatelli MC: Prenatal diagnosis and screening of the haemoglobinopathies. Bailliere's Clin Haematol 1998; 11: 215-238.

40 Jaffe A, Bush A: Cystic fibrosis: review of the decade. Monaldi Arch Chest Dis 2001; 56: 240-247.

41 Shulman LP, Sherman E: Cystic fibrosis. Metab Genet screen 2001; 28: $383-393$

42 Dodge JA: Neonatal screening for cystic fibrosis. Cystic fibrosis should be added to diseases sought in all newborn babies. BMJ 1998; 317: 411.

43 Murray J, Cuckle H, Taylor G, Littlewood J, Hewison J: Screening for cystic fibrosis. Health Technol Assess 1999; 3: 1-104.

44 Nippert I, Clausen H, Frets P, Niermeijer MF, Modell M: Evaluating cystic fibrosis carrier screening development in Northern Europe: Denmark, the Federal Republic of Germany, the Netherlands, and the United Kingdom. Münster: Westfälische WilhelmsUniversität; 1998, vol. 2, no. 1, p 114.
45 Wald NJ, Morris JK: Neonatal screening for cystic fibrosis. BMJ 1998; 316: 404-405.

46 Wildhagen MF, ten Kate LP, Habbema JD: Screening for cystic fibrosis and its evaluation. Br Med Bull 1998; 54: 857-875.

47 Wildhagen MF, Hilderink HB, Verzijl JG et al: Costs, effects, and savings of screening for cystic fibrosis gene carriers. J Epidemiol Community Health 1998; 52: 459-467.

48 Young SS, Kharrazi M, Pearl M, Cunningham G: Cystic fibrosis screening in newborns: results from existing programs. Curr Opin Pulm Med 2001; 7: 427-433.

49 Mischler EH, Wilfond BS, Fost N et al: Cystic fibrosis newborn screening: impact on reproductive behavior and implications for genetic counseling. Pediatrics 1998; 102: 44-52.

$50 \mathrm{NIH}$ : Consensus Development Conference Statement on Genetic Testing for Cystic Fibrosis. Arch Intern Med 1999; 159: $1529-1539$

51 Maheshwari M, Vijaya R, Kabra M et al: Prenatal diagnosis of Duchenne muscular dystrophy. Natl Med J India 2000; 13: 129-131.

52 Bradley DM, Parsons EP: Newborn screening for Duchenne muscular dystrophy. Semin Neonatol 1998; 3: 27-34.

53 Parsons EP, Clarke AJ, Hood K, Lycett E, Bradley DM: Newborn screening for Duchenne muscular dystrophy: a psychosocial study. Arch Dis Child Fetal Neonatal Ed 2002; 86: F91-F95.

54 Parsons EP, Bradley DM: Complementary methodologies in the evaluation of newborn screening for Duchenne muscular dystrophy. in Clarke AJ (ed): The genetic testing of children. Oxford: Bioscientific; 1998.

55 Wildhagen MF, van Os TA, Polder JJ, ten Kate LP, Habbema JD: Efficacy of cascade testing for fragile X syndrome. J Med Screen 1999; 6: 70-76.

56 Kallinen J, Heinonen S, Mannermaa A, Ryynanen M: Prenatal diagnosis of fragile $\mathrm{X}$ syndrome and the risk of expansion of a premutation. Clin Genet 2000; 58: 111-115.

57 Murray J, Cuckle H, Taylor G, Hewison J: Screening for fragile X syndrome: information needs for health planners. J Med Screen 1997; 4: 60-94.

58 Melis MA, Addis M, Lepiani C, Congeddu E, Cossu P, Cao A: A strategy for fragile-X carrier screening. Genet Test 1999; 3 : 301-304.

59 Turner G, Robinson H, Wake S, Laing S, Partington M: Case finding for the fragile $\mathrm{X}$ syndrome and its consequences. $B M$ ) 1997; 315: 1223-1226.

60 Ryynänen M, Heinonen S, Makkonen M, Kajanoja E, Mannermaa A, Pertti K: Feasibility and acceptance of screening for fragile $\mathrm{X}$ mutations in low-risk pregnancies. Eur J Hum Genet 1999; 7: 212-216.

61 The American College of Medical Genetics: Policy statement: Fragile X syndrome - diagnostic and carrier testing, 1994.

62 Humphries SE, Galton D, Nicholls P: Genetic testing for familial hypercholesterolaemia: practical and ethical issues. Q J Med 1997; 90: 169-181.

63 Kastelein JJ: Screening for familial hypercholesterolaemia. Effective, safe, treatments and DNA testing make screening attractive. BMJ 2000; 321: 1483-1484.

64 Marks D, Wonderling D, Thorogood M, Lambert H, Humphries SE, Neil HA: Screening for hypercholesterolaemia versus case finding for familial hypercholesterolaemia: a systematic review and cost-effectiveness analysis. Health Technol Assess 2000; 4 : $1-123$.

65 Nicholls P, Young I, Lyttle K, Graham C: Screening for familial hypercholesterolaemia. Early identification and tratment of patients is important. BMJ 2001; 322: 1062.

66 Wray R, Neil H, Rees J: Screening for hyperlipidaemia in childhood. Recommendations of the British Hyperlipidaemia Association. J R Coll Physicians Lond 1996; 30: 115-118.

67 Newman TB, Garber AM: Cholesterol screening in children and adolescents. Pediatrics 2000; 105: 637-638.

68 Senior V, Marteau TM, Peters TJ: Will genetic testing for predisposition for disease result in fatalism? A qualitative 
study of parents responses to neonatal screening for familial hypercholesterolaemia. Soc Sci Med 1999; 48: 1857-1860.

69 Lashley FR: Genetic testing, screening, and counseling issues in cardiovascular disease. J Cardiovasc Nurs 1999; 13: 110-126.

70 Defesche JC, Kastelein JJ: Molecular epidemiology of familial hypercholesterolaemia. Lancet 1998; 352: 1643-1644.

71 Marang-van de Mheen PJ, van Maarle MC, Stouthard ME: Getting insurance after genetic screening on familial hypercholesterolaemia: the need to educate both insurers and the public to increase adherence to national guidelines in The Netherlands. J Epidemiol Community Health 2002; 56: $145-147$.

72 Niederau C, Strohmeyer G: Srategies for early diagnosis of haemochromatosis. Eur J Gastroenterol Hepatol 2002; 14: 217-221.

73 Feder JN, Gnirke A, Thomas W et al: A novel MHC class I-like gene is mutated in patients with hereditary haemochromatosis. Nat Genet 1996; 13: 399-408.

74 Byrnes V, Ryan E, Barrett S, Kenny P, Mayne P, Crowe J: Genetic hemochromatosis, a Celtic disease: is it now time for population screening? Genet Test 2001; 5: 127-130.

75 Tavill AS: Cinical implications of the hemochromatosis gene. $N$ Eng J Med 1999; 341: 755-757.

76 Power TE, Adams PC: Psychosocial impact of C282Y mutation testing for hemochromatosis. Genet Test 2001; 5: 107-110.

77 Bassett ML, Leggett BA, Halliday JW, Webb S, Powell LW: Analysis of the cost of population screening for haemochromatosis using biochemical and genetic markers. $J$ Hepatol 1997; 27: 517-524.

78 Vautier G, Murray M, Olynyk JK: Hereditary haemochromatosis: detection and management. Med J Aust 2001; 175: 418-421.

79 Burke W, Franks Al, Bradley LA: Screening for hereditary hemochromatosis: are DNA-based tests the answer? Mol Med Today 1999; 5: 428-430.

80 The European and UK Haemochromatosis Consortia: Diagnosis and management of haemochromatosis since the discovery of the HFE gene: a European experience. Br J Haematol 2000; 108: 31-39.

81 Bradley LA, Haddow JE, Palomaki GE: Population screening for haemochromatosis: a unifying analysis of published intervention trials. J Med Screen 1996; 3: 178-184.

82 Burke W, Thomson E, Khoury MJ et al: Hereditary hemochromatosis: gene discovery and its implications for population-based screening. JAMA 1998; 280: 172-178.

83 Beutler E, Felitti YJ: The C282Y mutation does not shorten life span. Arch Intern Med 2002; 27: 1196-1197.

84 Haddow JE, Bradley LA: Hereditary haemochromatosis: to screen or not. BMJ 1999; 319: 531-532.

85 McCullen MA, Crawford DH, Hickman PE: Screening for hemochromatosis. Clin Chim Acta 2002; 315: 169-186.

86 ANAES (National Agency for Accreditation and Evaluation in Health): Evaluation clinique et économique: intérêt du dépistage de l'hémochromatose génétique en France. Paris: ANDEM; 1999.

87 Stuhrmann M, Notker G, Thilo D, Schmidtke J: Mutation screening for prenatal and presymptomatic diagnosis: cystic fibrosis and haemochromatosis. Eur J Pediatr 2000; 159 (Suppl 3): S186-S191.

88 Witte DL, Crosby WH, Edwards CQ, Fairbanks VF, Mitros FA: Practice guideline development task force of the College of American Pathologists. Hereditary hemochromatosis. Clin Chim Acta 1996; 245: 139-200.

89 Myles J, Duffy S, Nixon R et al: Initial results of a study into the effectiveness of breast cancer screening in a population identified to be at high risk. Rev Epidemiol Sante publ 2001; 49: $471-475$.

90 Young SR, Brooks KA, Edwards JG, Smith ST: Basic principles of cancer genetics. J SC Med Assoc 1998; 94: 299-305.

91 Aktan-Collan K, Mecklin JP, de la Chapelle A, Peltomaki P, Uutela A, Kaariainen H: Evaluation of a counselling protocol for predictive genetic testing for hereditary non-polyposis colorectal cancer. J Med Genet 2000; 37: 108-113.

92 Lenoir GM: Genetic predisposition to cancer development. Rev Prat 1995; 45: 1889-1894.

93 Aktan-Collan K, Mecklin JP, Jarvinen $\mathrm{H}$ et al: Predictive genetic testing for hereditary non-polyposis colorectal cancer: uptake and long-term satisfaction. Int J Cancer 2000; 89: 44-50.

94 The American Society of Clinical Oncology: Statement of the American Society of Clinical Oncology: genetic testing for cancer susceptibility, Adopted on February 20, 1996. J Clin Oncol 1996; 14: 1730-1736, discussion 1737-1740.

95 Eisinger F, Alby N, Bremond A et al: Recommendations for medical management of hereditary breast and ovarian cancer: the French National Ad Hoc Committee. Ann Oncol 1998; 9: 939-950.

96 Burke W, Petersen G, Lynch P et al: Recommendations for follow-up care of individuals with an inherited predisposition to cancer. I. Hereditary nonpolyposis colon cancer. Cancer Genetics Studies Consortium. JAMA 1997; 277: 915-919.

97 Burke W, Daly M, Garber J et al: Recommendations for follow-up care of individuals with an inherited predisposition to cancer. II. BRCA1 and BRCA2. Cancer Genetics Studies Consortium. JAMA 1997; 277: 997-1003.

98 Eisinger F, Burke W, Sobol H: Management of women at high genetic risk of ovarian cancer. Lancet 1999; 354: 1648.

99 Burke W, Coughlin SS, Lee NC, Weed DL, Khoury MJ: Application of population screening principles to genetic screening for adult-onset conditions. Genet Test 2001; 5: $201-211$.

100 Kronborg O: Screening for early colorectal cancer. World J Surg 2000; 24: 1069-1074.

101 Li FP: Cancer control in susceptible groups: opportunities and challenges. J Clin Oncol 1999; 17: 719-725.

102 Hodgson S, Milner B, Brown I et al: Cancer genetics services in Europe. Dis Markers 1999; 15: 3-13.

103 Lane B, Challen K, Harris HJ, Harris R: Existence and quality of written antenatal screening policies in the United Kingdom: postal survey. BMJ 322, 2001; 22-23.

104 Haddow JE, Palomaki GE, Bradley LA: Doherty RA: Screening for cystic fibrosis. JAMA 1998; 279: 1068-1069.

105 Modell B, Harris R, Lane B et al: Informed choice in genetic screening for thalassaemia during pregnancy: audit from a national confidential inquiry. BMJ 2000; 320: 337-341.

106 Cao A, Rosatelli MC, Galanello R: Control of beta-thalassaemia by carrier screening, genetic counselling and prenatal diagnosis: the Sardinian experience. Ciba Found Symp 1996; 197: 137-155.

107 Modell M, Wonke B, Anionwu E et al: A multidisciplinary approach for improving services in primary care: randomised controlled trial of screening for haemoglobin disorders. BMJ 1998; 317: 788-791.

108 Rowley PT, Loader S, Levenkron JC: Cystic fibrosis carrier population screening: a review. Genet Test 1997; 1: 53-59.

109 Cuckle HS: Extending antenatal screening in the UK to include common monogenic disorders. Community Genet 2001; 4: 8486.

110 Henneman L, ten Kate LP: Preconceptional couple screening for cystic fibrosis carrier status: couples prefer full disclosure of test results. J Med Genet 2002; 39: E26.

111 Chadwick R, Ten Have H, Husted J et al: Genetic screening and ethics: European perspectives. J Med Philos 1998; 23: 255-273.

112 McGleenan T: Genetic testing and screening: the developing European jurisprudence. Human reproduction and genetic ethics 1999; 5: 11-19.

113 Aghababian V, Auquier P, Hairiou D et al: Diagnostic génétique prénatal: comparaison des législations en Europe. J Med Légale Droit Méd 1997; 40: 441-449.

114 Danish Council of Ethics: Ethics and Mapping of the Human Genome. Copenhagen: Danish Council of Ethics; 1993.

115 The German Society of Human Genetics: Statement on heterozygote screening, 1991. 
116 The Health Council of the Netherlands: Committee Genetic Screening, Genetic Screening, The Hague, 1994.

117 Nuffield Council on Bioethics: Genetic Screening Ethical Issues, 1993.

118 WHO: WHO, Guidelines on ethical issues in medical genetics and the provision of genetic services. Geneva: WHO; 1995.

119 WHO: WHO Technical report series, control of hereditary diseases. Geneva: WHO; 1996.

120 WHO: WHO Human genetics programme, proposed international guidelines on ethical issues in medical genetics and genetic services. Geneva: WHO; 1997.

121 The Royal College of Physicians of London: Purchasers' Guidelines to Genetics Services in the NHS. London: The Royal College of Physicians of London; 1991.

122 Krawczak M, Cooper DN, Schmidtke J: Estimating the efficacy and efficiency of cascade genetic screening. Am J Hum Genet 2001; 69: 361-370.

123 Holloway S, Brock DJ: Cascade testing for the identification of carriers of cystic fibrosis. Med Screen 1994; 1: 159-164.

124 Brock DJ: Population screening for cystic fibrosis. Curr Opin Pediatr 1996; 8: $635-638$

125 Modell B: Delivering genetic screening to the community. Ann Med 1997; 29: 591-599.

126 Bennett R: Antenatal genetic testing and the right to remain in ignorance. Theor Med Bioethics 2001; 22: 461-471.

127 Freda MC, DeVore N, Valentine-Adams N, Bombard A, Merkatz IR: Informed consent for maternal serum alpha-fetoprotein screening in an inner city population: how informed is it? Obstet Gynecol Neonatal Nurs 1998; 27: 99-106.

128 Denayer L, Welkenhuysen M, Evers-Kiebooms G, Cassiman JJ, Van den Berghe H: Risk perception after CF carrier testing and impact of the test result on reproductive decision making. Am J Med Genet 1997; 69: 422-428.

129 Mennie ME, Axworthy D, Liston WA, Brock DJ: Prenatal screening for cystic fibrosis carriers: does the method of testing affect the longer-term understanding and reproductive behaviour of women? Prenat Diagn 1997; 17: 853-860.

130 Macklin R: Understanding informed consent. Acta Oncol 1999; 38: $83-87$.

131 Edwards SJ, Lilford RJ, Thornton J, Hewison J: Informed consent for clinical trials: in search of the 'best' method. Soc Sci Med 1998; 47: $1825-1840$.

132 ASHG: ASHG statement. Professional disclosure of familial genetic information. The American Society of Human Genetics Social Issues Subcommittee on Familial Disclosure. Am J Hum Genet 1998; 62: 474-483.

133 Smith K: Genetic testing of the general population: ethical and informatic concerns. Crit Rev Biomed Eng 2000; 28: 557-561.

134 Elias S, Annas GJ: Generic consent for genetic screening. N Engl J Med 1994; 330: 1611-1613.

135 Caulfield T: The commercialization of human genetics: profits and problems. Mol Med Today 1998; 4: 148-150.

136 Holtzman NA, Watson MS: Promoting safe and effective genetic testing in the United States. Final Report of the Task Force on Genetic testing. Baltimore, MD: Johns Hopkins University Press; 1997.

137 Cho MK, Sankar P, Wolpe PR, Godmilow L: Commercialization of BRCA1/2 testing: practitioner awareness and use of a new genetic test. Am J Med Genet 1999; 83: 157-163.

138 Giardiello FM, Brensinger JD, Petersen GM et al: The use and interpretation of commercial APC gene testing for familial adenomatous polyposis. $N$ Engl J Med 1997; 336: 823-827.

139 Cuckle HS, Lilford R, Wilson J, Sehmi I: Direct marketing of cystic fibrosis carrier screening: commercial push or population need? J Med Genet 1995; 33: 758.

140 Kaufert PA: Health policy and the new genetics. Soc Sci Med 2000; 51: 821-829.

141 Chadwick R, Ten Have H, Hoedemaekers R et al: Euroscreeen 2: towards community policy on insurance, commercialization and public awareness. J Med Philos 2001; 26: 263-272.
142 Caulfield T: The commercialization of human genetics in canada: an overview of policy and legal issues. in Knoppers BM (ed): Socio-ethical issues in human genetics. Montreal: Les Editions Yvon Blais Inc.; 1998, pp 343-402.

143 Dequeker E, Cassiman JJ: Evaluation of CFTR gene mutation testing methods in 136 diagnostic laboratories: report of a large European external quality assessment. Eur J Hum Genet 1998; 6: $165-175$.

144 The Advisory Committee on Genetic Testing: New guidelines for postal genetic testing. Genethics News 1997; 15: 3 .

145 King D: Genetic testing by post: how should it be controlled. Genethics News 1997; 15: 7.

146 Hoedemaekers R: Commercialisation - topics for reflection. Euroscreen newsletter, issue 10, Autumn: 1998.

147 The Report of the French National Consultative Ethics Committee: Opinions and Recommendations on Genetics and Medicine: from Prediction to Prevention, Reports, Paris, 1995, in French National Consultative Ethics Committee for Health and Life Sciences, Opinions, Recommendations, Reports 19841997, Levallois-Perret, Biomédition, 1998.

148 Terrenoire G: Le rôle des associations. in Comité consultatif national d'éthique pour les sciences de la vie et de la santé (dir.) Génétique et médecine, de la prédiction à la prévention. Paris: Documentation française; 1997, pp 135-137.

149 Green A: Neonatal screening: current trends and quality control in the United Kingdom. Rinsho Byori 1998; 46: 211-216.

150 Simonsen H, Brandt NJ, Norgaard-Pedersen B: Neonatal screening in Denmark. Status and future perspective. Ugeskr Laeger 1998; 28: 5777-5782.

151 Jorgensen FS, Valentin L, Salvesen KA et al: MULTISCAN - a Scandinavian multicenter second trimester obstetric ultrasound and serum screening study. Acta Obstet Gynecol Scand 1999; 78: 501-510.

152 Wald NJ, Watt HC, Hackshaw AK: Integrated screening for Down's syndrome on the basis of tests performed during the first and second trimesters. N Engl J Med 1999; 341: 461-467.

153 Girodon Boulandet E, Cazeneuve C, Goossens M: Screening practices for mutations in the CFTR gene ABCC7. Hum Mutat 2000; 15: $135-149$.

154 Elles R: An overview of clinical molecular genetics. Mol Biotechnol 1997; 2: 95-104.

155 Peckham CS, Dezateux C: Issues underlying the evaluation of screening programmes. Br Med Bull 1998; 54: 767-778.

156 Robson J: Screening in general practice and primary care. $\mathrm{Br}$ Med Bull 1998; 4: 961-982.

157 Stewart S, Stone D: Screening in Scotland. Health Bull (Edinb) 1996; 54: 13-15.

158 Stoddard JJ, Farrell PM: State-to-state variations in newborn screening policies. Arch Pediatr Adolesc Med 1997; 151: 561-564.

159 Sherriff R, Best L, Roderick P: Population screening in the NHS: a systematic pathway from evidence to policy formulation. I Public Health Med 1998; 20: 58-62.

160 Dezateux C: Evaluating newborn screening programmes based on dried blood spots: future challenges. Br Med Bull 1998; 54: 877-890.

161 Romano PS, Waitzman NJ: Can decision analysis help us decide whether ultrasound screening for fetal anomalies is worth it? Ann NY Acad Sci 1998; 847: 154-172.

162 Parsons EP, Bradley DM, Clarke AJ: Disclosure of Duchenne muscular dystrophy after newborn screening. Arch Dis Child 1996; 74: 550-553.

163 Uttermann G: Genetic services in Austria. Eur J Hum Genet 1997; 5 (Suppl 2): 31-34.

164 von Koskull H, Salonen R: Genetic services in Finland. Eur J Hum Genet 1997; 5 (Suppl 2): 69-75.

165 Schroeder-Kurth T: Screening in Germany: carrier screening, prenatal care and other screening projects. in Chadwick R, Shickle D, Ten Have H, Wiesing U (eds): The ethics of genetic screening. Dordrecht: Kluwer Academic Publishers; 1999, pp 81-87. 
166 Bartsocas CS: Genetic services in Greece. Eur J Hum Genet 1997; 5 (Suppl 2): 89-92.

167 Ferrari M: Consistency in ethical reasoning concerning genetic testing and other health related practices in occupational and non-occupational settings, Brussels, European Commission, 1998-2001, (europa.eu.int/comm/research/biosociety/pdf/ bmh4_ct98_3479_partb.p).

168 Ministry of Health and Social Affairs: Biotechnology related to human beings. Report no. 25 to the Storting Norway: Oslo; 1993.

169 Tranebjaerg L, Borresen-Dale AL, Hansteen IL, Heim S, Kvittingen EA, Moller P: Genetic services in Norway. Eur J Hum Genet 1997; 5 (Suppl 2): 130-134.

170 Ramos-Fuentes F: Genetic testing in Spain. in Karlic H, Horak A (eds): Proceedings of the genetic testing in Europe: harmonisation of standards and regulations. Austria: Ludwig Boltzmann Institute for Leukemia Research and Hematology, Hanusch Hospital \& General Directorate VI, Federal Chancellery Austria; 1998, pp 26-30.

171 Kristofferrson U: Genetic services in Sweden. Eur J Hum Genet 1997; 5 (Suppl 2): 169-173.

172 Pescia G: Genetic services in Switzerland. Eur J Hum Genet 1997; 5 (Suppl 2): 174-177.

173 House of Commons Select Committee on Science and Technology: Human Genetics: the Science and Its Consequences. Third Report, HMSO: 1995.

174 Council of Europe: Recommendation on Prenatal Genetic Screening, Prenatal Gentic Diagnosis and Associated Genetic Counselling, 1990.

175 Council of Europe: Recommendation on genetic testing and screening for health-care purposes of the European Committee of Ministers, 1992.

176 Council of Europe: Recommendation on Screening as a Tool of Preventive Medicine of the European Committee of Ministers, 1994.

177 Council of Europe: Convention for the Protection of Human Rights and Dignity of the Human Being with Regard to the Application of Biology and Medicine. April: 1997.

178 UNESCO: International bioethics Committee, Report of the Working Group on Genetic Screening and Testing, 1994.

179 UNESCO: The Universal Declaration on the Human Genome and Human Rights. November: 1997.

180 HUGO: Statement on the Principled Conduct of Genetics Research, 1995.

\section{Appendix A: \\ International and national regulatory frameworks European Countries}

Austria The Gene Technology Act (Law BGB 510/1994), 1994: This law regulates the use of genetic testing and gene therapy in human beings. Part IV of the legislation addresses the issue of genetic screening; the legislation imposes conditions requiring the fully informed consent of the individual to be screened (Section 65). The consent requirements also apply to the use of prenatal genetic screening techniques. Section 64 stipulates that 'DNAbased screening may be carried out but imposes a number of conditions so that screening may only be carried out where it is at the request of a doctor specialising in medical genetics or a doctor for the respective speciality and either for verification of a predisposition to a late onset disorder or for verification of carrier status or the diagnosis of an existing disease or late onset disorder. DNA-based screening may also be carried out as part of preparation for gene therapy and the monitoring of the effectiveness of any gene therapy treatment'. ${ }^{112}$

According to the Act, premises, where genetic tests for the diagnosis of a predisposition or for the identification of a carrier status of inherited diseases are performed, have to be approved by the Ministry of Health and Consumer Protection. For the authorization of premises for the performance of predictive genetic testing on humans, certain requirements have to be fulfilled. These requirements pertain to the structural and apparative condition of the premises, an adequate qualification and experience of the performing staff and sufficient measures for quality assurance, in order to ensure that genetic tests are carried out according to the state of the art and that the data gained from these tests are strictly protected. Genetic counselling has to be carried out before and after genetic testing, and has to include psychological or social aspects. If all these requirements are met, the premises will be approved by the competent authority on the basis of the opinion given by the relevant scientific committee of the gene technology commission. ${ }^{163}$

Belgium Although there is little specific legislation relating to genetics a Higher Council on Human Genetics was established in 1973. In 1987, a Crown Order established standards which must be met by any centre operating in the field of human genetics. In 1992, the Belgian parliament enacted the Law on Insurance Contracts that precluded insurance companies from using genetic testing in the determination of life or health insurance contract. The same law prohibits a candidate to communicate genetic information to the insurer, thus indirectly prohibiting the latter to request such information.

\section{Denmark}

- Danish Council of Ethics, Protection of Sensitive Personal Information - A Report, Copenhagen, 1992

- Danish Council of Ethics, Ethics and Mapping of the Human Genome, Copenhagen, 1993: See the section on 'The Danish Council of Ethics, ethics and mapping of the human genome'.

- Danish Council of Ethics, Genetic Screening - A Report, Copenhagen, 1993: This report recommended that all genetic screening projects should be ethically evaluated by the Central Scientific Committee (which approve all medical research involving human beings) as well as by the Council of Ethics itself. The report also stated principles for the information of persons to be tested, and for the evaluation of the consequences of genetic screening.

- Danish Centre for Human Rights, Genetic Test, Screening and Use of Genetic Data by Public Authorities in Criminal Justice, Social Security and Alien and Foreigners Acts, Copenhagen, 1993 
- Danish National Board of Health, Guidelines and recommendations for indications for prenatal diagnosis, 1994

- Danish Council of Ethics, Priority-setting in the Health Services, 1997: Genetic screening is mainly regulated through the legal regulations that in general applies to the Danish health care system.

Finland In 1997, the Ministry of Social Affairs and Health set up a Working Party to evaluate genetic screening programmes and the ethical and social issues involved with it. The Working Party gave its report in 1998: the main conclusion was that genetic screening programmes should always be approved by an official health care authority; the details of this should be legislated. There should be a national board of experts who should follow the research and practices concerning genetic screening.

There is no specific regulations of genetic testing in laboratories. The Ministry of Social Affairs and Health supervises genetic testing as part of supervision and quality control of both the public sector and the private laboratories. Recommendations on quality control have been published and updated several times by the Society for Medical Genetics. ${ }^{164}$

- Primary Health Care Act and Decree, 1971: This Act regulates the duties of municipalities regarding screenings. For the patients all screenings are voluntary.

- Act on the Status and Rights of patients, 785/1992: The act regulates, that is, patient's right to be informed about his/her state of health, patient's right to self-determination, drafting and keeping patient documents and confidentiality of information in patient documents.

- Gene Technology Act, 1995: This act aims to promote the safe use and development of gene technology.

- The Ministry of Social Affairs and Health, Report of a Working Party on Genetic Screening, 1998.

\section{France}

- Laws No. 94-653 of 29 July 1994 on respect for the human body: This law modifies the Civil Code by introducing notably the notions of the fundamental right to respect for one's body, therapeutic necessity as the only acceptable reason for violating bodily integrity and this only if the individual has consented. A genetic test can only be carried out for medical or scientific purposes, and only after consent has been obtained from the individual. Strict penalties are provided if case abuse occurs.

- Laws No. 94-654 of 29 July 1994 on the donation and use of elements and products of the human body, medically assisted procreation and prenatal diagnosis: Prenatal diagnosis is defined as including medical techniques aimed at detecting in utero a particularly severe disorder but not necessarily incurable. It must be preceded by a medical genetic counselling consultation. The cytogenetic and biological analyses must be carried out in authorized establishments. Preimplantation diagnosis is only allowed in certain circumstances: a physician working in a pluridisciplinary prenatal diagnosis center must attest that a couple runs a high risk of having a child suffering from a particularly severe genetic disease that is incurable at the time of diagnosis; the genetic anomaly must have been identified in one of the parents; both members of the couple must give written consent to the test. The purpose of the test is limited to finding the affection, and looking for ways to prevent and treat it.

- National Ethical Consultative Committee for the Life and Health Sciences in France, Genetics and Medicine: From Prediction to Prevention, Paris, 1995: Genetic screening is the subject of this report, which in the absence of a specific law, declares the ethical principles that must be respected, with respect to all the activities involved in genetic screening. Its recommendations cover the following topics and ethical principles: respect of the autonomy of the subject, respect of medical confidentiality; respect of privacy in computerizing personal data; the use of biological samples; the prohibition of using results of genetic tests for purposes other than medical or scientific; procedures of accreditation of the materials involved in genetic testing; prior evaluation of the impact of the tests; information and formation of all medical personnel in genetics; the need to guarantee correct public information; prohibition of all uses that would contribute to stigmatization or unfair discrimination in the social and economic spheres.

- National Advisory Committee on Bioethics and National College of Gynaecologists and Obstetricians Guidelines, 1997: The topics covered by these guidelines are prenatal diagnosis, preimplantation diagnosis and predictive testing for late-onset diseases.

- National Consultative Ethics Committee, Review of the Law No 94-653 of 29 July 1994: propositions regarding preimplantation diagnosis and prenatal diagnosis, 1998

- Parliamentary Office for Evaluating Scientific and Technological Choices, Report on the application of the law of 29 July 1994 concerning the donation and use of elements of the human body, medically assisted procreation and prenatal diagnosis, 1999: This report will serve as the basis for the parliamentary discussion scheduled for the second semester of 2000.

Germany The various States of the Republic of Germany have State Boards of Physicians who have to ratify the guidelines of the Federal Medical Association in order to put them in action. The States have no regulatory legislation on screening.

- The German Bundestag, Chancen und Risken der Gentechnologie Enquete-Commission, 1987: Prenatal diagnosis and 
newborn screening programmes were accepted. The document recommended the creation of a number of new offences in the German Criminal Code including the creation of a new offence of manipulating the germ line of a human being, and recommended a new criminal offence where an employer discriminates against an employee on the basis of the results of his genetic test. The report also contained detailed recommendations on the consent and counselling requirements which must be fulfilled before any genetic screening can be carried out. In most instances, the report did not recommend that legislation be enacted but rather that these matters be supervised by authoritative professional bodies. ${ }^{112}$

- The Embryo Protection Law of 1990: This law regulates medical actions around in vitro reproduction. It forbids by penalty to manipulate the embryos, to start more than three embryos, they are for implantation only. IVF is restricted to cases of infertility.

- Bundesministerium für Forschung und Technologie, Die Erforschung des menschlichen Genoms. Ethische und soziale Aspekte, 1990: The Federal Ministry of Research and Technology established a working group in order to evaluate the Ethical and Social Aspects of the Human Genome Analysis. Population screening and its problems was evaluated, as well as the screening with versus without medical indication and the necessity of informed consent $v s$ informed refusal. ${ }^{165}$

- Berufsverband Medizinische Genetik, Stellungnahme zu einem möblichen Heterozygoten - Screening bei Cystischer fibrose, Medizinische Genetik, 1990: The German Medical Genetics Association published a Statement about Screening of Heterozygotes pointing to the danger of discrimination of carriers within an uneducated society. ${ }^{165}$

- The German Society of Human Genetics, ${ }^{115}$ Statement on heterozygote screening, 1991: The German Society states that for population screening, the public must be fully and competently educated about the project and that there be guarantees that participation of the examinees is voluntary, that the examinees are able to comprehend the significance of their decision, that the individuals responsible for counselling and examination are qualified to do so, and that possible risks be evaluated beforehand. Therefore, the German Society rejects this type of population screening at present since the basic preconditions are not met. This applies to education of the public, the guarantee that the required counselling is qualified, and the carrying out of scientific projects on which future decisions can be based.

- Bundesärztekammer, Memorandum, Genetisches Screening, Deutsches Ärzteblatt 89, 25126, 1992: The Scientific Council of the German Federal Board of Physicians Medical Association Memorandum dealt with population carrier screening. This influential Memorandum pointed to the missing goal of population screening of genetic defects for everybody when testing for average risks. ${ }^{165}$

- The German Society of Human Genetics, Statement on genetic diagnosis in childhood and adolescence, 1995

- The German Society of Human Genetics, Guidelines for molecular genetic diagnosis, 1996

- The German Society of Human Genetics, Guidelines for genetic counselling, 1996

- The German Society of Human Genetics, Position Paper, 1996: This paper defines standards for the application of genetic tests to nearly all fields of practical genetics: heterozygosity testing and screening, genetic testing in children, prenatal diagnosis, predictive testing.

- The Professional Association of Medical Genetics, Principles of genetic counselling, 1996

- Wissenschaftlicher Beirat der Bundesârztekammer, Richtlinien zur pränatalen Diagnostik von Krankheiten und Krankheitsdispositionen, Deutsches Arzteblatt 95, C-22843242, 1998: These guidelines for prenatal diagnosis of disorders and dispositions for diseases describes the indications for any invasive interventions, goals and conditions like counselling before and after the test. Maternal serum screening has been emphasized as an appropriate and valid methodology.

- Wissenschaftlicher Beirat der Bundesârztekammer, Richtlinien zur Diagnostik der genetischen Dispositionen für Krebserkrankungen, Deutsches Arzteblatt 95, B-1120-1127, 1998: These guidelines for diagnosing genetic dispositions for cancer state that diagnoses for patients suffering from cancer are differentiated from screening for dispositions in healthy persons who have some indications for this test and who need to be counselled before and after the test. Otherwise, any patient in ambulances or clinics has a right to get diagnosed and to learn about the nature of his disease.

In Germany, there is a special committee that, all 1-3 years, publishes consensus resolutions and guidelines as to maternal serum screening: Northelmer Konsensus-Tagungen.

- Rauskolb R, Blutuntersuchungen bei Schwangeren zur pränatalen Erkennung von Chromosomenanomallen und Neuralrohrdefekten (sog. Triple-Test), Der Frauenarzt 1993; 34: 254-258.

- Braulke I, Rauskolb R, Blutuntersuchungen bei Schwangeren zur pränatalen Diagnostik von Chromosomenanomallen und Neuralrohrdefekten (sog. Triple-Test), Bericht ber die 2, Konsenstagung, Der Frauenarzt 1995; 36: 98-99.

- Braulke I, Rauskolb R, Blutuntersuchungen bei Schwangeren zur pränatalen Risikopräzislerung für Chromosomenanomallen und Neuralrohrdefekten (sog. Triple-Test), Med Genet 1996; 4: 348-352.

- Pauer HU, Rauskolb R, Blutuntersuchungen bei Schwangeren zur pränatalen Risikopräzislerung für Chromosomenanomallen und Neuralrohrdefekten (sog. Triple-Test), Der Frauenarzt, 1999; 40: 518-522. 
- The fifth Consensus Conference, First trimester screening in Germany, 1999

- Wissenschaftlicher Beirat der Bundesârztekammer, Richtlinien zur Durchfuehrung der assistierten Reproduktion, Deutsches Arzteblatt 95, C-2230-2235, 1998: In this professional guidelines for IVF, no other indications than those authorized by the Embryo Protection Law are accepted. Preimplantation diagnosis is not allowed.

Attempts are being made by some institutions today to review and discuss the technical possibilities of PGD, the question of its necessity, and the ethical, social and legal problems, in particular the necessary changes of the Embryo Protection Law and the professional guidelines for IVF. In addition, the reformed Abortion Law of 1995 still bans abortion but allows exceptions under certain conditions. The jurisdiction in the German constitution protects the diseased or disabled. Therefore a future disorder or disability of the foetus can not be used as sole reason for abortion. These principles cause difficulties in discussions pro PGD.

Greece In 1977, Greek legislation changed the abortion law to allow termination of the pregnancy up to the 24th week for medical reasons. There is no legislation concerning practice in genetics. Currently, a five-member Bioethics Committee, reporting directly to the Prime Minister is preparing guidelines regarding the ethical and social issues of genetic testing. Since 1981, the Hellenic Association of Medical Genetics has been trying to get approval from the government concerning a national genetics programme that would include all the existing units and establish new units of genetics all over the country under specific structure and organization. Quality control systems are not existent and the Hellenic Association of Medical Genetics has not been involved up until today in the organisation of such a system. ${ }^{166}$

Iceland Iceland has no law that specifically deals with human genetics. There is a law (no. 18/1996) on genetically engineered organisms. The law on patients' rights (no. 74/1997) has some relevance here, as do laws on health-care service $(97 / 1990)$, on personal privacy and data protection (121/1989), and some other laws (eg 53/1988, 37/1993, 50/1996).

- Act no. 121/1989 on Personal Privacy and Data Protection, Ministry of Health, 1989: The implementation of the Data Protection Act is monitored by the Data Protection commission, a special independent official agency, appointed by the Minister of Justice for a period of 4 years. The commission has an important role both as a standard setting and a monitoring body.

- Act no. 97/1990 on a Healthcare Services, Ministry of Health, 1990.
- Act no. 74/1997 on the Rights of Patients, Ministry of Health, 1997: This Act includes fundamental rights of patients including rules on consent, confidentiality and handling of information in clinical records.

- Act no. 139/1998 on a Health Sector Database, Ministry of Health, 1998: This Act is in compliance with the Act on the Rights of Patients. By reference to article 29 in the Act on the Rights of Patients, the Minister of Health and Social Security has issued a regulation on scientific research in the health sector (Reg. No. 552/1999) where a special Scientific Ethics Committee is founded. The Committee is given a specific role in the Act on HSD.

Ireland There are no specific regulations or laws in place regarding genetic testing. Similarly, no specific schemes are in place for the licensing or accreditation of laboratories involved in genetic testing.

\section{Italy}

- Legge No 104/5 febbraio 1992 (Gazzetta Ufficiale), Leggequadro per l'assistenza, l'integrazione sociale e i diritti delle persone handicappate

- The Italian Committee on Bioethics, Prenatal Diagnosis, 17 July 1992

- Legge No 548/23 dicembre 1993 (Gazzetta Ufficiale), Disposizioni per la prevenzione e la cura della fibrosi cistica

- The Italian Committee on Bioethics, Identity and Rights of the Embryo, 22 June 1996

- The Italian Committee on Bioethics, Human Genome Project, 18 March 1994 and 21 February 1997

- National Guidelines for Genetic Testing, 1998: In May 1998, the Italian Government has approved the National Guidelines for Genetic Testing prepared by a Task Force. The general objectives are: (1) ensuring the safety and effectiveness of both existing and newly introduced genetic tests; (2) defining the criteria for quality assurance of laboratories performing genetic tests; (3) ensuring both adequate counselling and the free decision of individuals and families; this will include a particular attention to problems concerning ethics and privacy. Some topics deserving a specific concern have been identified, namely: genetic testing for prenatal diagnosis, genetic testing for susceptibility to cancer, and genetic testing for rare diseases. ${ }^{167}$

- Decreti presidenziali, 9 luglio 1999 (Gazzetta Ufficiale), Accertamenti per la diagnosi delle malformazioni (Art. 1): This decree address the screening of the following diseases: $\mathrm{CF}$, phenylketonuria and congenital hypothyroidism. It establish that these services must be free of charge.

- Law no. 675, 31 December 1996, D.P.R. no. 318, 28 July 1999, on Medical Information Privacy

- The Italian Committee on Bioethics, Orientamenti bioetici per i test genetici, 19 November 1999: Genetic information 
must be treated as the general medical information and therefore it is forbidden to give this information to insurers or employers without consent.

\section{Norway}

- Ministry of Health and Social Affairs, ${ }^{168}$ Biotechnology Related to Human Beings, Report No. 25 to the Storting, Oslo, 1992-1993: Screening shall only take place if it offers clear therapeutic benefits for the individual.

- Act Relating to the Application of Biotechnology in Medicine, Law no. 56 of 5 August 1994: This Act gives a frame of general guidelines for assisted reproductive technology applications, research on embryos, preimplantation diagnosis, prenatal diagnosis, genetic testing after birth and gene therapy. This Act also specifies obligations about authorization of institutions applying medical biotechnology and the duty for such institutions to report regularly on their activities to the Ministry of Health and Social Affairs. ${ }^{169}$

Genetic testing for diagnostic purposes is permitted without restrictions, but the law requires that comprehensive genetic counselling be given before, during and after genetic tests performed on healthy persons for presymptomatic, predictive or carrier purposes. Presymptomatic, predictive and carrier testing is limited to individuals above the age of 16 years. When the information refers to a diagnostic test, genetic results may be communicated, without restrictions, between medical institutions authorized to apply medical biotechnology. However, the exchange of genetic information about presymptomatic, predictive or carrier tests is restricted. The Act states that it is prohibited to ask whether a presymptomatic, predictive or carrier test has been performed. Gene therapy is only allowed as somatic cell therapy and individuals below the age of 16 years need the consent of their parents or guardians. ${ }^{169}$

Portugal The Ratification of the 'Convention for the Protection of Human Rights and Dignity of the Human Being and the additional protocol on the prohibition of cloning human beings' was published in January 2001. Since 1995, the Ministry of Health has named a task force in order to prepare guidelines for medical genetics and prenatal diagnosis.

- Act No. 10/95 related to the Protection of Personal Information

- Despacho Ministerial No. 9108/97, Guidelines for Molecular Genetic Diagnosis

- Circular normativa No. 6/DSMIA/DGS, 1997, Recommendations for Maternal Serum screening Programs

- Despachos Ministerials No. 5411/97 e No 10325/99, Principles and Practice for prenatal diagnosis

- Convention for the Protection of Human Rights and Dignity of the Human Being and the additional protocol on the prohibition of cloning human beings, 2001

Spain There is no specific legislation to ensure the appropriateness of genetic procedures and the confidentiality of personal data. Consent to undergo to any medical tests is granted through General Health Law of 25 April 1986; article 10.6 states the right of a patient to choose freely between options given by the physician in charge of his case. Protection of data related to health may be reached through general rules concerning personal data protection, as well as through provisions which recognise the duty of confidentiality in the health field. The Organic Law regulating the automated processing and protection of personal data of 13 December 1999 provides special measures of protection for personal health data. Among other fundamental rights, the general legal principle of non discrimination is stated by the Spanish Constitution of 1978 , which forbids any kind of discrimination on grounds of any personal condition. ${ }^{170}$

Quality assessment schemes for genetic services have been addressed in specific areas. In 1996, standard criteria for quality control of cytogenetic and prenatal diagnosis laboratories were issued, and currently there are plans to develop quality standards for clinical and molecular genetic services. ${ }^{170}$

In September 1999, Spain subscribed and joined the European Agreement for the Protection of Human Rights and Dignity of the Human Being with regard to the Application of Biology and Medicine.

- The Spanish Constitution of 1978

- Protocolos de Procedimientos Diagnosticos y Terapeuticos. Obstetricia. Medicina Materno Infantil (SEGO), Madrid 1985

- General Health Law of 25 April 1986

- The Royal Decree of 21 November of 1986: This Decree rules out the conditions for the Centers to be authorized to perform therapeutic abortion, preimplantation and prenatal tests, as well the requisites to be filled in by practitioners concerned.

- The Act 35/1988 of 22 November on Techniques of Assisted Reproduction, 1988: This law regulates the human reproduction techniques when they are performed by a specialist in authorized public or private medical centers. Article 12 regulates preimplantation and prenatal diagnosis. Articles 14-17 permit investigation and experimentation for the treatment and prevention of genetic disorders under determined conditions. Article 159 permits that manipulation of human genes only when the intention is the elimination or the improvement of a serious illness.

- Ministry of Health, Handbook for Prenatal Diagnosis, Madrid, 1989

- The Organic Law regulating the automated processing of personal data of 29 October 1992 
- Recomendaciones y Protocolos en Diagnostico Prenatal. Report of the European Study Group on Prenatal Diagnosis, 1993

- Guidelines for prenatal cytogenetics, 1996

- The Organic Law regulating the automated processing and protection of personal data of 13 December 1999

- Catalan agency for health technology assessment and research, Prenatal screening of cystic fibrosis, 2000: The proposes were: According to the available scientific evidence on the efficacy and effectiveness of prenatal screening of $\mathrm{CF}$, the implementation of a systematic, general screening programme for $\mathrm{CF}$ in all newborns in Catalonia is not recommended. Coordinated international studies, presenting new scientific evidence on the effectiveness of the early diagnosis and treatment of CF are required - it is unlikely that the Catalan data alone would provide with a conclusive answer to this issue.

\section{Sweden}

- National Board of Health and Social Welfare, Neonatal screening for metabolic diseases, SOSFS, 1988

- Law 114 of March 1991 on the Use of Certain Gene Technologies within the Context of General Medical Examinations (1993): This law examines the use of certain genetic technology in medical screening. There must be a permission from the National Board of Health and Welfare. Authorization from this body is required before DNA testing can be carried out. This requirement extends to the use of genetic screening techniques for diagnostic purposes.

- Swedish Society for Medical Genetics, 1994: The Swedish Society for Medical Genetics has brought forward a quality assessment document for clinical genetic units including guidelines for cytogenetic and molecular routines as well as for genetic counselling. This document has been adopted by all the university clinical genetic departments as a minimum standard for quality. ${ }^{171}$

- The Ministry of Health and Social Affairs, Guidelines on the use of prenatal diagnosis and preimplantation diagnosis, 1995: These guidelines regulate prenatal diagnoses and include prenatal diagnosis by genetic tests. All pregnant women must be informed about prenatal diagnosis. Screening is in principle to be avoided in connection with prenatal diagnosis. Preimplantation diagnosis may only be used for the diagnosis of serious, progressive, hereditary diseases, which lead to premature death and for which there is no cure or treatment.

- National Board of Health and Social Welfare, Genetics in Health Care: Guidelines, 1999

- The Agreement between the Swedish government and the Association of insurance companies, 1999: According to this agreement, the use of information about an individual that has been obtained by studying his genetic characteristics other than for medical purposes is prohibited. This agreement is valid to the year 2002 .

\section{Switzerland}

- The Swiss Federal Constitution, 1992: The Constitution provides laws on human genetic practice and medicalassisted procreation. Article 119 (introduced in 1992 as article 24 novies, old numbering) paragraph 2 states that the genetic make-up of an individual may be investigated, registered or divulged only with his consent or on the basis of a legal prescription. Article 24 novies forbids preimplantation diagnosis in either clinical or research settings.

- The Swiss Academy of Medical Sciences, Medical-ethical Guidelines for Genetic Investigations in Humans, Approved by the Senate of the Swiss Academy of Medical Sciences on 3 June 1993: Although there are no official national standards for genetic counselling, the medical-ethical guidelines define the content of genetic counselling in connection with genetic investigation for all physicians. ${ }^{172}$ The medical-ethical guidelines also define the spectrum of activities belonging to genetic services in general. Quality control standards exist for laboratory investigations.

The Swiss Academy of Medical Sciences guidelines are not legally binding, unless cantonal legislation gives them binding force.

- Bill regarding Genetic Investigations in Humans, September 1998: This bill has not yet been debated in Parliament. Section 2 allows genetic investigations for medical purposes. Article 10 describes conditions for genetic screening.

\section{The Netherlands}

- The Population Screening Act, 1992 (1996): This act states that screening by means of ionizing radiation, screening for cancer and screening for serious disorders for which there is no treatment are not allowed without ministerial approval, based on the advice and assessment of the Health Council. A license may be refused if the screening programme is scientifically unsound, if it conflicts with statutory regulations or if the risks are found to outweigh any benefits.

- The Health Council of The Netherlands: Committee Genetic Screening, Genetic Screening, The Hague, 1994: See the section on The Health Council of The Netherlands: Committee Genetic Screening, Genetic Screening.

The United Kingdom Following the publication of the House of Commons Select Committee on Science and Technology's report (1995), the Department of Health 
established an advisory sub-committee, The Human Genetics Advisory Commission, which provides advice relating to genetic testing and screening. In 1998, The United Kingdom planed to introduce a new Data Protection Act to implement the terms of the Privacy Directive enacted by the European Union in $1995 .{ }^{112}$ The aim of this Directive is the harmonization of data protection laws in Europe in order to facilitate the development of medical research while maximizing the protection of individual privacy.

- Royal College of Physicians, Prenatal Diagnosis and Genetic Screening Community and Service Implications, London, 1989

- Royal College of Physicians, Purchasers' Guidelines to Genetic Services in the NHS, London, 1991

- The Nuffield Council on Bioethics, Genetic Screening: Ethical Issues, 1993: See the section on The Nuffield Council on Bioethics, Genetic Screening: Ethical Issues.

- Working Party of The Clinical Genetics Society, A Report on Genetic Testing of Children, 1994

- House of Commons Select Committee on Science and Technology, ${ }^{173}$ human Genetics: the Science and Its Consequences, Third Report, HMSO, 1995: This report examines the ethical issues arising from genetic technology and recommends the setting up of a Human Genetics Commission to regulate the advance of genetic technology.

- The British Hyperlipidaemia Association, Screening for hyperlipdemia in childhood: Recommendations, 1996

- The Advisory Committee of Genetic Testing, Code of Practice and Guidance on Human Genetic Testing Services Supplied Direct to the Public, 1997

- The Advisory Committee on Genetic Testing, A report on Genetic Testing for Late Onset Disorders, 1998: The Advisory Committee on Genetic Testing aims in this report is to set out the issues to be considered before genetic testing for late onset disorders is offered and during the provision of such tests. The major issues relate principally to requests for genetic testing from healthy relatives of patients with a late-onset genetic disorder. Population-based genetic screening, diagnostic testing of symptomatic individuals and genetic susceptibility testing for common disorders are briefly considered.

- The Royal College of Physicians, Clinical Genetic Services: Activity, Outcome, Effectiveness and Quality, London: Royal College of Physicians, 1998

- The Nuffield Council on Bioethics, Mental Disorders and Genetics: The Ethical Context, 1998

- Human Fertilisation \& Embryology Authority, Code of Practice, 1998

- Genetic Interest Group, Guidelines for Genetic Services, London, G.I.G., 1998

- Genetic Interest Group, Confidentiality Guidelines, London, G.I.G., 1998
- General Medical Council, Seeking patients' consent: the ethical considerations, London: General Medical Council, 1999: This guidance on screening spells out what this should include: the purpose of the screening, the likelihood of positive/negative results, the uncertainties and risks attached to the screening process, any significant medical, social, or financial implications of screening for the particular condition or predisposition, and follow-up plans, including the availability of counselling and support services.

- Department of Health, Second Report of the UK National Screening Committee, London, Department of Health, 2000: This report contains five chapters: (1) screening policymaking - getting research into practice; (2) organizing screening programmes; (3) the NSC's forward programme; (4) a protocol for pilot management; and (5) the NSC's recommendations since 1998. The NSC's recommendations are for adult programmes (abdominal aortic aneurysms, diabetic retinopathy, vascular disease, osteoporosis, cardiomyopathy, ovarian cancer, and prostate cancer), antenatal programme (syphilis) and child health programme.

\section{European institutions}

- Council of Europe, Recommendation on Prenatal Genetic Screening, Prenatal Genetic Diagnosis and Associated Genetic Counselling, $1990^{174}$

- Council of Europe, ${ }^{175}$ Recommendation on genetic testing and screening for health-care purposes of the European Committee of Ministers (1992, n. R92, 3): All members of the Council of Europe adopted this Recommendation, except the Netherlands.

- Council of Europe, Recommendation on Screening as a Tool of Preventive Medicine of the European Committee of Ministers, $1994^{176}$

- Council of Europe, Privacy Directive 94/46, 1995

- Council of Europe, ${ }^{177}$ Convention for the Protection of Human Rights and Dignity of the Human Being with Regard to the Application of Biology and Medicine, 1997: The Convention is the first internationally-binding legal text designed to protect people against the misuse of biological and medical advances. This text has legal effect in the Council of Europe's member States that have ratified it. Each state then has to bring its laws into line with the Convention. Belgium, Germany, Ireland, and the United Kingdom have not yet signed the Convention and it is no force until it is signed and implemented into the national law.

The Convention sets out to preserve human dignity, rights and freedoms, through a series of principles and prohibitions. It does not refer explicitly to genetic screening, at most according to Article 5, a genetic test 'may only be carried out after the person concerned has given free and informed 
consent to it'; according to Article 12, 'tests which are predictive of genetic diseases or which serve either to identify the subject as a carrier of a gene responsible for a disease or to detect a genetic predisposition or susceptibility to a disease may be performed only for health purposes or for scientific research linked to health purposes, and subject to appropriate genetic counselling'. The restriction of genetic diagnostics to health or scientific purposes is reinforced by Article 11 that states that 'any form of discrimination against a person on grounds of his or her genetic heritage is prohibited'. However, the Convention does not say whether individuals who have had a genetic test for health or scientific purposes will be required to disclose the results of that test to an insurance company or an employer.

The Convention has endorsed the Council of Europe recommendations on genetic screening.

- Council of Europe, Recommendation 1512 on the protection of the human genome, 2001

\section{Australia}

- Human genetic Society of Australasia, Newborn Screening, 1999: The HGSA proposed general recommendations for newborn screening: Newborn screening is recommended provided that: (i) there is benefit for the individual from early diagnosis. (ii) The benefit is reasonably balanced against financial and other costs. (iii) There is a reliable test suitable for newborn screening. (iv) There is a satisfactory system in operation to deal with diagnostic testing, counselling, treatment and follow-up of patients identifies by the test.

- Human Genetic Society of Australasia, Guidelines for the Practice of Genetic Counselling, 1999: This guidelines concerns the general practice of genetic counselling. However, the following citation refers to screening tests: 'Screening tests are non-diagnostic, population-based tests providing the client with a personalised risk. When performed prenatally, screening tests may identify fetal abnormalities or reveal an increased risk of fetal abnormalities. When performed post-natally, the aim of genetic screening is to identify individuals at increased risk of developing symptoms of a disorder in the future, with a view to offering intervention eg, newborn screening. The nature of a screening test should be clearly distinguished from a diagnostic test to the client. Appropriate written and/or verbal information should be provided prior to testing. Support and counselling should be made available to persons receiving a high-risk result so that future options are understood.'

\section{United States of America}

- The ASHG Policy Statement for Maternal Serum alphafetoprotein Screening Programs and Quality Control for
Laboratories Performing Maternal Serum and Amniotic Fluid alpha-fetoprotein Assays, 1987

- Statement of The ASHG on Cystic Fibrosis Carrier Screening, 1990

- Statement of The ASHG on Cystic Fibrosis Carrier Screening, 1992

- American Medical Association, E-2.137 Ethical Issues in Carrier Screening of Genetic Disorders, 1994: The Association recommends that all carrier testing must be voluntary, and informed consent from screened individuals is required. Confidentiality of results is to be maintained. Results of testing should not be disclosed to third parties without the explicit informed consent of the screened individual. Patients should be informed as to potential uses for the genetic information by third parties, and whether other ways of obtaining the information are available when appropriate. Carrier testing should be available uniformly among the at-risk population being screened. One legitimate exception to this principle is the limitation of carrier testing to individuals of childbearing age. In pursuit of uniform access, physicians should not limit testing only to patients specifically requesting testing. If testing is offered to some patients, it should be offered to all patients within the same risk category. The direction of future genetic screening tests should be determined by well thought out and well-coordinated social policy. Third parties, including insurance companies or employers, should not be permitted to discriminate against carriers of genetic disorders through policies that have the ultimate effect of influencing decisions about testing and reproduction.

- The ACMG Clinical Practice Committee, Principles of screening, 1997: The American College emphasizes the following points:

- A screening programme should have a clearly defined purpose, whether the purpose is research or medical care

- A screening programme is more than a laboratory test. Therefore, follow-up evaluation and counselling by genetic professionals must be guaranteed.

- A screening programme should be reviewed by the appropriate board and be evaluated periodically to determine if it is meeting its goals.

- The ACMG, Policy Statement: Fragile X Syndrome Diagnostic and Carrier Testing, 1997

- The ACMG, Standards and Guidelines for Clinical Genetics Laboratories, Second Edition, 1999: These voluntary standards are an educational resource to assist medical geneticists in providing accurate and reliable diagnostic genetic laboratory testing consistent with currently available technology and procedures in the areas of clinical cytogenetics, biochemical genetics and molecular diagnostics. These standards establish minimal criteria for clinical genetics laboratories. The Standards 
should not be considered inclusive of all proper procedures and tests or exclusive of other procedures and tests that are reasonably directed to obtaining the same results. The accuracy and dependability of all procedures should be documented in each laboratory. This should include in-house validation and/or references to appropriate published literature. Specialized testing, not available to all laboratories, requires appropriate and sufficient documentation of effectiveness to justify its use. In determining the propriety of any specific procedure or test, the medical geneticist should apply his/her own professional judgment to the specific circumstances presented by the individual patient or specimen. Medical geneticists are encouraged to document the reasons for the use of a particular procedure or test, whether or not it is in conformance with these Standards. These Standards will be reviewed and updated periodically to assure their timeliness in this rapidly developing field.

- The ACMG, Laboratory Standards and Guidelines for Population-based Cystic Fibrosis Carrier Screening, 2001: The Committee recommends that CF carrier screening be offered to non-Jewish Caucasians and Ashkenazi Jews, and made available to other ethnic and racial groups who will be informed of their detectability through educational brochures, the informed consent process, and/or other efficient methods. For example, Asian Americans and Native Americans without significant Caucasian admixture should be informed of the rarity of the disease and the very low yield of the test in their respective populations. Testing should be made available to African Americans, recognizing that only about 50\% of at-risk couples will be detected. An educational brochure and a consent form which recites this information as well as a sign-off for those choosing not to be tested after reading these materials is being prepared by the Working Group on Patient Education and Informed Consent.

- American Medical Association, Report 4 of the Council on Scientific Affairs (I-O1) Newborn Screening: Challenges for the Coming Decade, 2001: The AMA:

(1) Supports the report from the Newborn Screening Task Force, 'Serving the Family from Birth to the Medical Home: A Report from the Newborn Screening Task Force,' and recognizes the authors of this report as the major stakeholders in the field of newborn.

(2) Supports the Health Resources and Services Administration, Centers for Disease Control and Prevention, and the American College of Medical Genetics as they study the process of standardization of outcomes and guidelines for state newborn screening programs.

(3) Will monitor developments in newborn screening and revisit the topic as necessary.
- American Academy of Pediatrics, Ethical Issues With Genetic Testing in Pediatrics (RE9924), 2001: The AAP has adopted these recommendations:

(1) Established newborn screening tests should be reviewed and evaluated periodically to permit modification of the programme or elimination of ineffective components. The introduction of new newborn screening tests should be conducted through carefully monitored research protocols.

(2) Genetic tests, like most diagnostic or therapeutic endeavors for children, require a process of informed parental consent and the older child's assent. Newborn screening programmes are encouraged to evaluate protocols in which informed consent from parents is obtained. The frequency of informed refusals should be monitored. Research to improve the efficiency and effectiveness of informed consent for newborn screening is warranted.

(3) The AAP does not support the broad use of carrier testing or screening in children or adolescents. Additional research needs to be conducted on carrier screening in children and adolescents. The risks and benefits of carrier screening in the pediatric population should be evaluated in carefully monitored clinical trials before it is offered on a broad scale. Carrier screening for pregnant adolescents or for some adolescents considering pregnancy may be appropriate.

(4) Genetic testing for adult-onset conditions generally should be deferred until adulthood or until an adolescent interested in testing has developed mature decision-making capacities. The AAP believes that genetic testing of children and adolescents to predict late-onset disorders is inappropriate when the genetic information has not been shown to reduce morbidity and mortality through interventions initiated in childhood.

(5) Because genetic screening and testing may not be well understood, pediatricians need to provide parents the necessary information and counseling about the limits of genetic knowledge and treatment capabilities, the potential harm that may be done by gaining certain genetic information, including the possibilities for psychological harm, stigmatization, and discrimination, and medical conditions and disability and potential treatments and services for children with genetic conditions. Pediatricians can be assisted in managing many of the complex issues involved in genetic testing by collaboration with geneticists, genetic counsellors, and prenatal care providers.

(6) The AAP supports the expansion of educational opportunities in human genetics for medical students, residents, and practicing physicians and the expansion of training programmes for genetic professionals. 


\section{International organizations}

- WHO, Principles and Practice of Screening for Disease, Geneva: WHO, 1968: See the section on 'WHO guidelines for screening for Disease'.

- Council for International Organization of Medical Sciences, The Declaration of Inuyama, Human Genome Mapping, Genetic Screening and Gene Therapy, Geneva, 1990: The CIOMS recommended that: 'The central objective of genetic screening and diagnosis should always be to safeguard the welfare of the person tested: test results must always be protected against unconsented disclosure, confidentiality must be ensured at all costs, and adequate counselling must be provided.'

-WHO, Community Genetics Services in Europe, Geneva: WHO, 1991

- UNESCO, International Bioethics Committee, ${ }^{178}$ Report of the Working Group on Genetic Screening and Testing, 1994

- UNESCO, Report of Subcommittee on Bioethics and Population Genetics, Bioethics and Human Population Genetics Research, 1995

- WHO, Guidelines on Ethical Issues in Medical Genetics and the Provision of Genetic Services, Geneva: WHO, 1995

- WHO Technical Report Series, Control of Hereditary Diseases, Geneva: WHO, 1996

- WHO, Proposed International Guidelines on Ethical Issues in Medical Genetics and Genetics Services, Geneva: WHO, 1997

The World Health Organization emphasizes the following points:

- Genetic screening and testing should be voluntary

- Genetic screening and testing should be preceded by adequate information about the purpose and possible outcomes of the screen or test and potential choices to be made

- Results should not be disclosed to employers, insurers, schools or others without the individual's consent

- Test results should be followed by genetic counselling, particularly when they are unfavorable

- Newborn screening should be mandatory and free of charge if early diagnosis and treatment will benefit the newborn

- UNESCO, The Universal Declaration on the Human Genome and Human Rights, $1997^{179}$

- HUGO, Statement on the Principled conduct of Genetics Research, $1995^{180}$

\section{Appendix B}

\section{Contributions}

This document was reviewed by the ESHG Public and Professional Policy Committee (PPPC). Members of the PPPC were:

Ségolène Aymé (Paris, France) Chair

Martin Bobrow (Cambridge, UK)
Gerry Evers-Kiebooms (Leuven, Belgium)

Peter Farndon (Birmingham, UK)

Helena Kääriäinen (Helsinki, Finland)

Ulf Kristoffersson (Lund, Sweden)

Marcus Pembrey (London, UK)

Sandy Raeburn (Nottingham, UK)

Albert Schinzel, ( Zürich, Switzerland)

Joerg Schmidtke (Hannover, Germany)

Leo ten Kate (Amsterdam, The Netherlands)

Lisbeth Tranebjaerg (Copenhagen, Denmark) Secretary

This document was discussed during a workshop in Amsterdam (NL), 19-20 November, 1999 where 51 experts from 15 European countries were invited. The workshop was organized by Ségolène Aymé, Gerry Evers-Kiebooms, and Leo ten Kate.

The first draft was sent out to a wide range of people and organizations for consultation. The following consultants sent in critical comments.

\section{Austria}

- Gerd Utermann, Institute of Medical Biology and Human Genetics, University of Innsbruck, Innsbruck

\section{Belgium}

- Maryse Bonduelle AZ VUB, Medical Genetics, Brussels

- Jean-Jacques Cassiman, Centre for Human Genetics, University of Leuven, Leuven

- Laurence Cordier, ELSA-Biotechnology, European Commission, Brussels

- Kris Dierickx, Centre of Medical Ethics and Law, School of Medicine, KU Leuven

- Anne Hagemeijer-Hausman, Center for Human Genetics, KU Leuven, Leuven

- Eric Legius, The Clinical Genetics Unit, University of Leuven, Leuven

- Herman Nys, Center for Bio-medical Ethics and Law, Catholic University, Leuven

- Jacques Rondal, European Down's Syndrome Association, Liege

- Erik Tambuyzer, Genzyme Corporate Affairs, Leuven

- Esther Vamos, Brugmann Hospital, Cytogenetics Laboratory, Brussels

\section{Cyprus}

- Kyproula Christodoulou, The Cyprus Institute of Neurology and Genetics, Nicosia

- Violetta Christophidou-anastasiadou, The Cyprus Institute of Neurology and Genetics, Nicosia

\section{Denmark}

- Lene Koch, Institute of Social Medicine, University of Copenhagen, Copenhagen 
- Lars Vejerslev, Department of Obstetrics and Gynaecology, Municipal Hospital, Holbaek

\section{Eastern Countries}

- Ivo Baric, Department of Paediatrics, University Hospital Centre, Zagreb

- Evgeny Ginter, Research Center for Medical Genetics/ Sciences, Moscow

- Georges Kosztolanyi, Department of Human Genetics and Teratology, National Institute of Hygiene, Budapest

- Maria Kucerova, Genetics Department, Thomayer University Hospital, Prague

- Vaidutis Kucinskas, Human Genetics Centre, Vilnius University, Vilnius

- Andres Metspalu, Institute of Molecular and Cellular Biology, Tartu University, Tartu

- Jiri Santavy, Dep Fetal Medicine, University Hospital, Olomouc

\section{Finland}

- Pertti Aula, member of the Working Party on Genetic Screening, Helsinki

- Riitta Salonen, department of obstetrics and Gynecology, Helsinki University Central Hospital, Helsinki

- Paivi Santalahti, University of Turku, Turku

\section{France}

- Association Hemochromatose France

- Romain Favre, Département d'Echographie et Médecine fotale, CMCO-SIHCUS, Schiltigheim

- Claude Ferec, Laboratoire de biologie génétique, Brest

- René Frydmann, Hôpital Antoine Béclère, Clamart

- Isabelle Hirtzlin, Centre de recherche en economie de la sante, INSERM U 357, Kremlin-Bicetre

- Claire Julian- Reynier, Institut Paoli Calmettes, Marseille

- Michèle Junière, Mosaiques - Association des X-fragiles

- Agnès Lordier-Brault, Direction Générale de la Santé, Paris

- Stanislas Lyonnet, Hôpital Necker -Enfants Malades, Paris

- Jean-Louis Mandel, Institut Génétique, Biologie moléculaire et cellulaire, Illkirch

- Virginie Scotet, Laboratoire de Biologie Génétique, Brest

- Gwen Terrenoire, Centre de Sociologie de l'éthique, CNRS, Paris

- Yves Ville, Centre Hospitalier Intercommunal PoissySaint Germain en Laye

\section{Germany}

- Irmgard Nippert, Institut für Humangenetik, Westfälische Wilhelms-Universität Münster, Münster

- U. Sancken, Institute of Human Genetics, Güttingen

- Traute Schröder-Kurth, Eibelstadt
- Klaus Zerres, Universitâtsklinikum der RWTH Aachen, Aachen

\section{Greece}

- Ariadni Mavrou, Genetic Unit, Department of Paediatrics, Athens University Medical School, Athens

- Catherine Metaxotou, Genetic Unit, Department of Paediatrics, Athens University Medical School, Athens

- Michael Petersen, Institute of Child Health, Athens

- Christos Yapijakis, Neurogenetics Unit, Athens

Italy

- Bruno Brambati, Mangiagalli Institute, First Clinic of Obstetrics and Gynaecology, University of Milan, Milan

- Lara Brambati, Mangiagalli Institute, First Clinic of Obstetrics and Gynaecology, University of Milan, Milan

- Antonio Cao, Istituto di Clinica e Biologia dell'Eta Evolutiva-Universita degli Studi di Cagliari

- Elisa Calzolari, Instituto Genetica Medizina, Ferrara

- Domenico Coviello, Modena

- Bruno Dallapiccola, Tor Vergata University, Roma

- Emilio Donti, Centre of Perinatal Medicine, University of Perugia

- Faustina Lalatta, Citogenetics, Milan

- Galanello Renzo, Istituto di Clinica e Biologia dell’Eta Evolutiva, Universita degli Studi di Cagliari, Cagliari

- Giovanni Neri, Instituto di Genetica umana, Universita Cattolica, Roma

\section{Norway}

- Tor Flage, National Board of Health, Oslo

- Trond Leren, Ulleval Hospital, Oslo

- Karen Orstavik, Dept. Medical Genetics, Ulleval Hospital, Oslo

\section{Portugal}

- Joao Lavinha, Centro de Genetica Humana, Lisbon

- Luis Nunes, Nucleo de Genetica e Diagnostico, PrenatalDireccao Geral Saude, Lisboa

- Heloisa Santos, Medical Genetics, Hospital de Santa Maria, Lisboa

- Jorge Sequeiros, ICBAS, Porto

\section{Spain}

- Joaquina Gabarron, Unidad Tecnica de Genetica Humana, Murcia

- Teresa Pàmpols, Institut de Bioquimica Clinica, Corporacio Sanitària Clinic, Barcelona

- Maria Ramos-Arroyo, Medical Genetics, Pamplona

- Feliciano Ramos Fuentes, Section of Genetics, Department of Pediatrics, University of Zaragoza, Zaragoza

- Alberto Valiente, Servicio de Genetica, Hospital Virgen Del Camino, Pamplona 


\section{Sweden}

- Lena Jonsson, Ministry of Health and Social Affairs, Stockholm

- Magnus Nordenskjöld, Department of Clinical Genetics, Stockholm

- The-Hung Bui, Department of Clinical Genetics, Karolinska Hospital, Stockholm

- Lars Hagenfeldt, The PKU Laboratory, Centre for Inherited Metabolic Diseases, Huddinge

\section{Switzerland}

- Stylianos Antonarakis, Division of Medical Genetics, CMU, Geneva

- Monica Gersbach-Forrer, Division of Medical Genetics, University Hospital, Geneva

- Sinuhe Hahn, Department of Obstetrics and Gynecology, University of Basel, Basel

- Wolfgang Holzgreve, University of Basel, Department of Obstetrics and Gynecology, Basel

\section{The Netherlands}

- Joep Defesche, Academic Medical Centre, Amsterdam

- Guido de Wert, Institute for Bioethics, Maastricht

- Nico Leschot, Department of Human Gentics, University of Amsterdam, Amsterdam

- Martinus Niermeyer, Erasmus University, Rotterdam

- Arie van Bellen, The alliance of patient and parent organizations

- Jan van Lith, Academic Medical Centre, Amsterdam

- Gert van Ommen, Leiden University Medical Center Faculty of Medicine, Leiden

- Mark Wildhagen, Department of Public Health, Erasmus University Rotterdam

\section{United Kingdom}

- Elisabeth Anionwu, Institut of child health, Mothercare pediatric genetics, London

- David Brock, Human Genetics Unit, The University of Edinburg, Edinburg

- Angus Clarke, Institute of Medical Genetics, University of Wales, Cardiff

- John Dodge, Department of Child Health, Singleton Hospital, Swansea

- Angela Flannery, R\&D Genetics, Discovery Research, Zeneca Pharmaceuticals, Cheshire

- Neva Haites, Department of Medical Genetics, Aberdeen Royal Hospitals NHS Trust, Aberdeen

- Hilary Harris, Wolfson Genetics Enquiry Centre, St Mary's Hospital, Manchester

- Rodney Harris, Wolfson Genetics Enquiry Centre, St Mary's Hospital, Manchester
- Shirley Hodgson, Genetics Centre, Guy's Hospital, London

- Liz Jazwinska, Biopharmaceutical Research 1 Development, SmithKline Beechmam, Harlow

- Alastair Kent, Genetic Interest Group, London

- Mairi Levitt, Centre for Professional Ethics, University of Central Lancashire, Preston

- Theresa Marteau, Psychology and Genetics Research Group, Guys Medical School, London

- Bernadette Modell, Department of primary care \& population services, Whittington Hospital, London

- Mike Modell, Department of primary care \& population services, Whittington Hospital, London

- Evelyn Parson, University of Wales College of Medicine, Cardiff

- David Porteous, Department of Medical Sciences, University of Edinburgh, Edinburgh

- David Shapiro, UNESCO, London

- Darren Shickle, School of Health and Related Research, University of Sheffield, Sheffield

- Rosalinda Snijders, Harris Birthright Research Centre for Fetal Medicine, London

- Maurice Super, Department of Clinical Genetics, Royal Manchester Children's Hospital, Manchester

\section{International}

- Agnes Bankier, Institute Royal Children's Hospital, Parkville, Australia

- Judith Hall, University of Vancouver, Vancouver, Canada

- Neil Holtzman, Department of Pediatrics, The Johns Hopkins University School of Medicine, Baltimore, USA

- Bartha-Maria Knoppers, Centre de Recherche en Droit Public, University of Montreal, Montreal

- Darryl Macer, University of Tsukuba, Japan

- Elaine Strass, The American Society of Human Genetics, Rockville, USA

- Dorothy Wertz, Eunice Kennedy Shriver Center, Waltham, USA

- Ellen Wright Clayton, Division of General Pediatrics, Medical Center East, Nashville, USA

This document forms part of a BIOTECH program financed by the Commission of the European Communities (CEE BIO4-CT98-0550).

All rights reserved. No part of this document may be reproduced or utilized in any form or by any means, electronic or mechanical, including photocopying, recording, microcoping, or by any information storage and retrieval system, without permission in writing from the copyright holder.

(C) Copyright 2000 by ESHG/PPPC 